\title{
Modeling and Optimization of Energy Hubs: A Comprehensive Review
}

\author{
Azadeh Maroufmashat ${ }^{1,}{ }^{*}$, Syed Taha Taqvi ${ }^{1}$, Amir Miragha ${ }^{2}$, Michael Fowler ${ }^{1}$ and \\ Ali Elkamel 1,3 \\ 1 Chemical Engineering Department, University of Waterloo, 200 University Ave W, \\ Waterloo, ON N2L 3G1, Canada \\ 2 Energy Research Institute, Nanyang Technological University (ERI@N), 1 CleanTech Loop, \#06-04, \\ Singapore 637141, Singapore \\ 3 Department of Chemical Engineering, Khalifa University, Abu Dhabi, United Arab Emirates \\ * Correspondence: Azadeh.mashat@gmail.com or amaroufm@uwaterloo.ca
}

Received: 28 June 2019; Accepted: 16 August 2019; Published: 23 August 2019

\begin{abstract}
The concept of energy hubs has grown in prominence as a part of future energy systems, driven by the spread of Distributed Energy Resources (DERs) and the inception of the smart grid. This paper systematically reviews 200 articles about energy hubs, published from 2007 to 2017, and summarizes them based on their modeling approach, planning and operation, economic and environmental considerations, and energy hub applications. The common applications of energy hubs are considered, such as distributed energy resources, the consideration of Plug-in Hybrid Electric Vehicles (PHEVs), and the hydrogen economy. This paper examines modeling approaches towards energy hubs, including storage and its network models; it mentions some of the optimization strategies used to tackle the efficient operation and control of energy hubs. The novelty of this work lies in the classification of research papers related to energy hubs, the development of a generic framework for modeling these multiple energy flow carriers with storage and network considerations, and the provision of solution techniques in line with energy hub optimization.
\end{abstract}

Keywords: energy hub; modeling and optimization; hydrogen economy; integrated energy systems

\section{Introduction}

Historically, synergy in energy systems has been of interest for decades, and several studies have addressed problems in synergistic optimal energy carriers. The energy hub approach, also known as multi-energy systems, has played a vital role in addressing such problems, and many researchers have utilized this methodology and extended this concept in modeling, optimization, and application. This review paper aims to organize and classify literature regarding multi-energy systems or "energy hubs", whilst identifying research gaps in this field of study. Moreover, this paper recommends new areas for further research as the subject matter will continue to develop significantly in the years to come.

In 2002, a research project entitled "Vision of Future Energy Networks (VoFEN)" was introduced, with the purpose of creating an optimal energy infrastructure for the target year of 2050 [1]. The project focused on developing a generic model and an analysis framework. In 2005, the same team introduced the concepts of energy hubs $(\mathrm{EH})$ and energy interconnectors $(\mathrm{EI})[2,3]$. The latter, though not within the scope of this study, were proposed as an application in multiple energy carrier transmission [4]. The research was carried out envisioning the difficulty of making traditional systems economically and environmentally sustainable [2,5]. By considering these bridging elements (i.e., energy hubs and interconnectors), Geidl et al. [4] believed that current sub-optimal energy systems can be transitioned to optimal systems. 


\subsection{What is An "Energy Hub"?}

Literature has referred to energy hubs as multi-energy systems, multiple energy carrier systems, multi-source multi-product systems, combined/hybrid energy systems, hybrid poly-generation energy systems, and distributed multi-generation systems. These hybrid energy systems can be described as integrated energy systems that consist of energy generation, conversion, and storage systems [6]. They are also defined as an interface between energy producers and consumers that are used to couple multiple energy carriers to meet different types of demands [1]. An energy hub receives inputs from various energy vectors. It is defined as a method to move and store energy, and includes, but is not limited to, electricity, natural gas (NG), heat, hydrogen, biogas, and liquid petroleum and alcohol fuels. Within such a hub, energy may be generated or transformed with technologies, such as wind turbines, solar photovoltaics, solar thermal technology, combined heat and power plants (CHP), heat exchangers, furnaces and boilers, and electrochemical devices, such as fuel cells. Energy can be stored in technologies, such as batteries, flywheels, and compressed air energy storage (CAES) systems in the form of hydrogen, or in thermal devices and arrays [7]. Energy hubs have been a topic of growing interest since their introduction by Geidl et al. in 2005 [6].

\subsection{Significance}

Current energy systems lack the following abilities: to accommodate increased future energy demand and to allow the integration of a large fleet of distributed energy resources (DERs) whilst meeting increasingly stringent environmental regulations [1]. They fail to manage the distribution of power based on user consumption at a regional scale, as well as the scale of small communities [8]. Additionally, concerns about energy efficiency are growing, as poly generation energy systems and decentralized generation technologies attract attention; thus, more flexible energy infrastructure is needed in terms of operation and distribution [8-10].

The Greenfield approach, used in other fields of study, advocates a strategy for designing future energy systems that eliminates constraints set by previous energy systems. Different forms of energy may be bridged together to establish synergism, as a fundamental step towards an optimum state. The linking of multiple energy carriers in centralized units was proposed in the early literature [1,4], i.e., energy hubs, where different forms of energy vectors may undergo transformation, conversion, and storage for later use. Devising and utilizing such bridging systems may lead to an optimal level of operation for energy systems. Figure 1 presents a schematic view for the transition to future energy systems.

This paper aims to organize and classify the literature regarding multi-energy systems or "energy hubs", whilst identifying research gaps in this field. Although some studies discuss the concept of energy hubs, a clear knowledge gap exists when reviewing modeling and optimization approaches. Moreover, these papers often fail to build upon the work carried out on the common theme of applications of smart energy systems. Therefore, this review paper is written to provide readers with comprehensive and clear insight into energy hubs and to uncover future research concepts. 


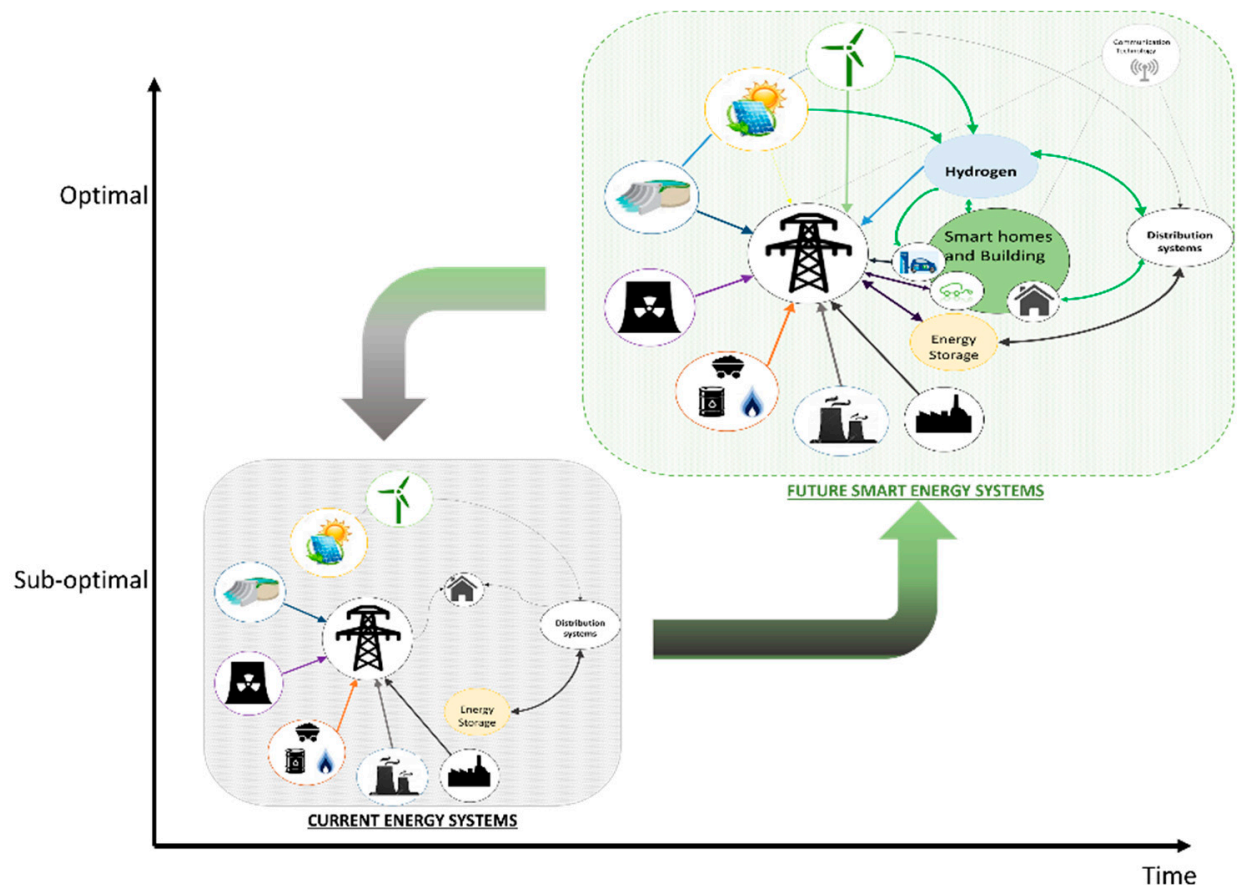

Figure 1. Transition of future energy systems.

\section{Literature Classification of Energy Hubs}

This section aims to organize and classify literature regarding multi-energy systems or "energy hubs", whilst identifying research gaps in this field of study. Figure 2 shows a concept map that outlines the areas highlighted in this paper.

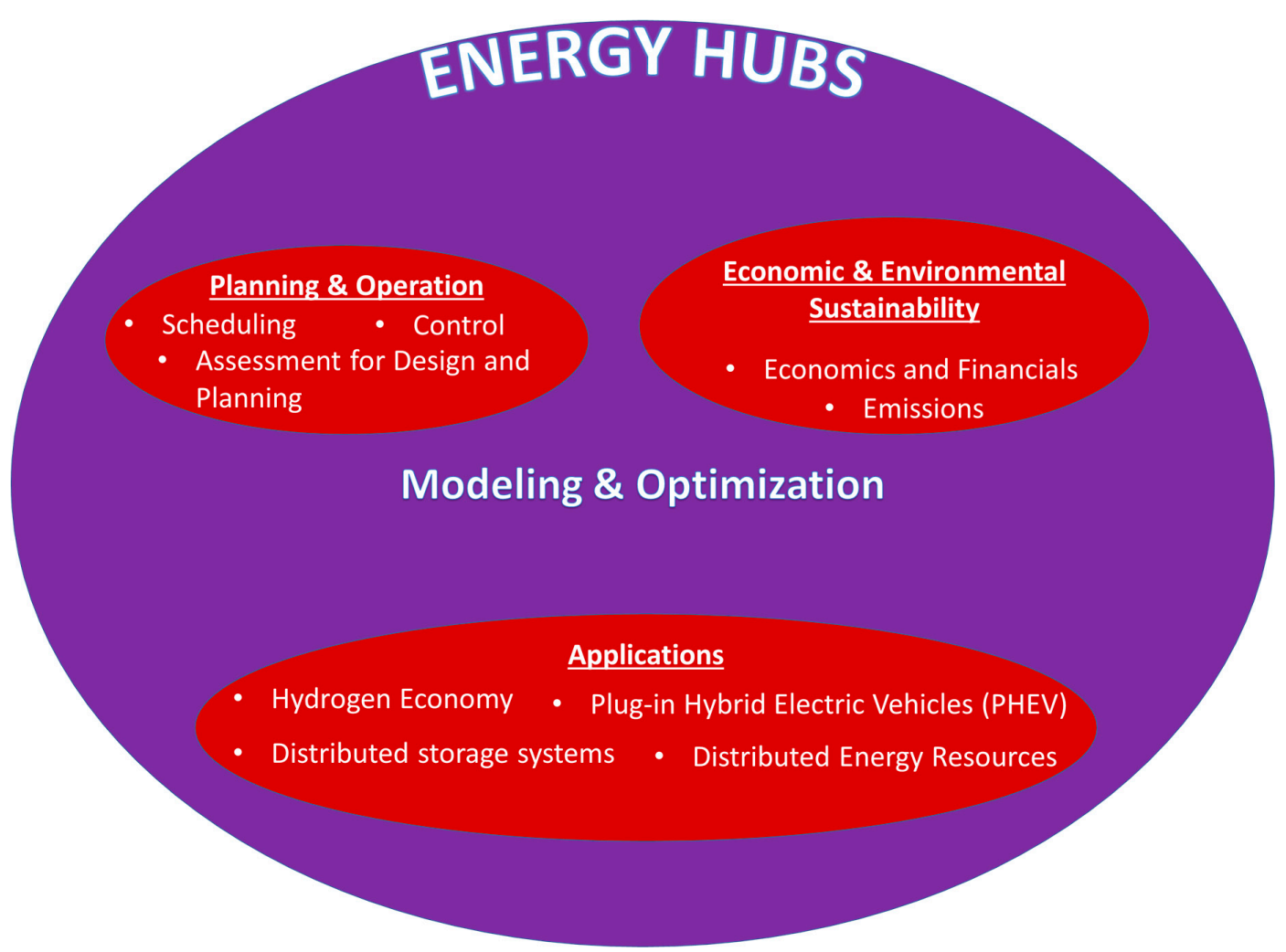

Figure 2. Concept map outlining the areas focused on in this paper. 
This review is comprised of three main parts: (i) introduction, (ii) modeling, and (iii) optimization. Along with the definition of an energy hub and an overview of its research initiation, the article classifies the literature to date. As evident from Figure 2, the research focuses on (a) planning and operation, (b) economic and environmental impacts, and (c) multiple applications of energy hubs. Each area is explored in detail.

Since the introduction of optimal multiple energy carrier systems, numerous studies have explored modifying and further developing them to enhance their reliability and control [11-14]. The concept of the energy hub has been applied across different regions and fields of study [15-17]. Planning of energy hub networks and their operation has been the focus of several research projects [18-21], especially for aspects pertaining to economics and the environment [22-24]. In addition, recent studies have looked at the concepts of an energy internet, smart energy hubs, virtual power plants, and smart grids based on the energy hub approach [25-31].

Table 1 lists review publications that discuss the concept of energy hubs within their study. However, when reviewing modeling and optimization approaches, a knowledge gap is evident.

Table 1. List of studies that review the energy hub concept.

\begin{tabular}{|c|c|c|}
\hline Paper & Area of Focus & Reference \\
\hline Geidl et al. (2007) & \multirow{6}{*}{ Energy hubs } & [1] \\
\hline Geidl et al. (2006) & & [2] \\
\hline Favre-Perrod (2005) & & [3] \\
\hline Geidl et al. (2007) & & [4] \\
\hline Krause et al. (2011) & & [32] \\
\hline Mohammadi et al. (2017) & & [33] \\
\hline Phdungsilp and Martinac (2016) & \multirow{5}{*}{ DER/DES } & {$[34]$} \\
\hline Mancarella (2014) & & [35] \\
\hline Chicco and Mancarella (2009) & & [36] \\
\hline Howell et al. (2017) & & [37] \\
\hline Houwing et al. (2006) & & [38] \\
\hline Alizadeh et al. (2016) & \multirow{3}{*}{ Renewable energy integration } & [39] \\
\hline Favre-Perrod et al. (2009) & & {$[40]$} \\
\hline Liserre et al. (2010) & & [41] \\
\hline Liu et al. (2014) & \multirow{4}{*}{$\begin{array}{c}\mathrm{CCHP} / \mathrm{CHP} \\
\text { Integrated gas and electricity }\end{array}$} & [42] \\
\hline Rubio et al. (2008) & & {$[43]$} \\
\hline Rubio-Barros et al. (2010) & & {$[44]$} \\
\hline Lund et al. (2016) & & [45] \\
\hline Mancarella et al. (2016) & \multirow{2}{*}{ Modeling/simulation } & [46] \\
\hline Allegrini et al. (2015) & & [47] \\
\hline Chiang and Zavala (2016) & Control & [48] \\
\hline Rong and Su (2017) & \multirow{3}{*}{ Planning and optimization } & [49] \\
\hline Rubio-Barros et al. (2012) & & {$[18]$} \\
\hline van Beuzekom et al. (2015) & & {$[50]$} \\
\hline Klöckl et al. (2005) & \multirow{2}{*}{ Need and impact of energy hubs } & [51] \\
\hline Shabanpour-Haghighi and Seifi (2016) & & [52] \\
\hline
\end{tabular}


In the following sections, relevant studies discussing the concept of energy hubs are chronologically listed in tables. These tables show the type of technologies and the energy vectors considered in the authors' literature survey and indicate whether storage technologies and energy hub networks were considered. Some studies may cover more than one area; however, they are listed only once in the area they are most closely associated with. Table 2 lists the acronyms and abbreviations used in this paper.

Table 2. Table of abbreviations/acronyms used within classification tables.

\begin{tabular}{cc}
\hline \multicolumn{2}{c}{ Transormation and Generation Technologies } \\
\hline CHP & Combined heat and power systems \\
\hline Micro & Microgrid \\
\hline Solar & Solar energy \\
\hline Wind & Wind energy \\
\hline Hydro & Hydropower \\
\hline & Energy Vectors \\
\hline Elec & Electricity \\
\hline NG & Natural Gas \\
\hline Heat & (District) Heat \\
\hline Bio & Biomass/biofuel \\
\hline H ${ }_{2}$ & Hydrogen \\
\hline Network & A network of energy hubs considered \\
\hline Storage & Storage technologies such as hydrogen batteries \\
\hline
\end{tabular}

\subsection{Planning and Operation}

According to the classification, more than 150 studies are relevant to this aspect. When examining the issue of the planning and operation of multiple energy systems, there are several factors that must be considered:

- The size or/and capacity of each convertor and/or storage technology within energy hubs;

- The type of conversion and storage technologies to be implemented within hubs;

- The control methodology of power flow within energy hubs.

These characteristics not only govern the overall operational efficiency of the energy system in general, but they also specifically determine the reliability of the system when subjected to an increasing load.

One of the earliest studies on the operation planning of synergistic systems using energy hubs was conducted by Unsihuay et al. [53]. The work aimed to minimize the operation costs for an integrated hydrothermal and gas system. Another study, conducted by Robertson et al. [54], outlined energy infrastructure for the UK, as it progressed towards a lower-carbon economy. It employed the energy hub approach to determine the framework that would allow the most effective conversion and transfer of energy. Galus and Andersson [55] carried out research focusing on planning the integration of plug-in hybrid electric vehicles (PHEVs) into energy hub networks; driving behavior was simulated and different conditions pertaining to vehicle usage were explored.

\subsubsection{Scheduling}

The scheduling of energy hubs is important in integrating energy systems, tackling energy shortages, lessoning environmental impacts [56], and reducing operational costs [21,57]. As multiple energy carriers enter an energy hub, deciding what type of source of energy will meet the specific load can be challenging. If intermittent sources of energy are involved (commonly renewables), 
effective planning can reduce the operational costs and harmful greenhouse gas (GHG) emissions, while ensuring reliability of the energy systems. Table 3 summarizes the publications on the scheduling of energy systems based on the concept of the energy hub.

Table 3. List of studies conducted on the scheduling of multi-energy carrier systems.

\begin{tabular}{|c|c|c|c|c|c|c|c|c|c|c|}
\hline \multirow{2}{*}{ Reference } & \multirow{2}{*}{ Paper } & \multicolumn{3}{|c|}{ Technology } & \multicolumn{4}{|c|}{ Energy Vectors } & \multirow{2}{*}{ Network } & \multirow{2}{*}{ Storage } \\
\hline & & CHP & Solar & Wind & Elec & NG & Heat & Bio & & \\
\hline [57] & Pazouki and Haghifam (2013) & $\checkmark$ & & $\checkmark$ & $\checkmark$ & $\checkmark$ & $\checkmark$ & & & Y \\
\hline [58] & Pazouki et al. (2013) & $\checkmark$ & & & $\checkmark$ & $\checkmark$ & $\checkmark$ & $\checkmark$ & & $\mathrm{Y}$ \\
\hline [59] & Haghifam et al. (2013) & $\checkmark$ & & $\checkmark$ & $\checkmark$ & $\checkmark$ & $\checkmark$ & & & $\mathrm{Y}$ \\
\hline [21] & Pazouki et al. (2013) & $\checkmark$ & & $\checkmark$ & $\checkmark$ & $\checkmark$ & $\checkmark$ & & & $\mathrm{Y}$ \\
\hline [60] & Rastegar and Fotuhi-Firuzabad (2014) & $\checkmark$ & & & $\checkmark$ & $\checkmark$ & $\checkmark$ & & & $\mathrm{Y}$ \\
\hline [61] & Pazouki (2015) & $\checkmark$ & $\checkmark$ & & $\checkmark$ & $\checkmark$ & $\checkmark$ & & & $\mathrm{Y}$ \\
\hline [62] & Xu et al. (2015) & $\checkmark$ & $\checkmark$ & & $\checkmark$ & $\checkmark$ & $\checkmark$ & & $\checkmark$ & $\mathrm{N}$ \\
\hline [63] & Ramírez-Elizondo and Paap (2015) & $\checkmark$ & & $\checkmark$ & $\checkmark$ & $\checkmark$ & $\checkmark$ & & & $\mathrm{Y}$ \\
\hline [64] & Vaccaro et al.(2015) & $\checkmark$ & & & $\checkmark$ & $\checkmark$ & $\checkmark$ & & & $\mathrm{N}$ \\
\hline [65] & Moghaddam et al. (2016) & $\checkmark$ & & & $\checkmark$ & $\checkmark$ & $\checkmark$ & & & $\mathrm{Y}$ \\
\hline [66] & Pazouki and Haghifam (2016) & $\checkmark$ & & $\checkmark$ & $\checkmark$ & $\checkmark$ & $\checkmark$ & & & $\mathrm{Y}$ \\
\hline [67] & Morvaj et al. (2016) & $\checkmark$ & & & $\checkmark$ & $\checkmark$ & $\checkmark$ & & $\checkmark$ & $\mathrm{Y}$ \\
\hline [68] & Zidan and Gabbar (2016) & $\checkmark$ & $\checkmark$ & $\checkmark$ & $\checkmark$ & $\checkmark$ & $\checkmark$ & & & $\mathrm{N}$ \\
\hline [69] & Moghaddam et al. (2016) & $\checkmark$ & & & $\checkmark$ & $\checkmark$ & $\checkmark$ & & & $\mathrm{Y}$ \\
\hline [70] & Pazouki (2016) & $\checkmark$ & $\checkmark$ & & $\checkmark$ & $\checkmark$ & $\checkmark$ & & & $\mathrm{Y}$ \\
\hline [71] & Moghaddam et al. (2016) & $\checkmark$ & & & $\checkmark$ & $\checkmark$ & $\checkmark$ & & & $\mathrm{Y}$ \\
\hline [56] & Fan et al. (2016) & $\checkmark$ & & & $\checkmark$ & $\checkmark$ & $\checkmark$ & & & $\mathrm{Y}$ \\
\hline [72] & Baghaee et al.(2016) & & $\checkmark$ & $\checkmark$ & $\checkmark$ & & & & & $\mathrm{Y}$ \\
\hline [73] & Zlotnik et al. (2017) & $\checkmark$ & & & $\checkmark$ & $\checkmark$ & $\checkmark$ & & $\checkmark$ & $\mathrm{N}$ \\
\hline [74] & El-Zonkoly (2017) & $\checkmark$ & & & $v$ & $\checkmark$ & $\checkmark$ & & & $\mathrm{Y}$ \\
\hline [75] & $\begin{array}{l}\text { Dolatabadi and Mohammadi-Ivatloo } \\
\text { (2017) }\end{array}$ & $\checkmark$ & & $\checkmark$ & $\checkmark$ & $\checkmark$ & $\checkmark$ & & & Y \\
\hline [76] & Chen et al. (2017) & $\checkmark$ & & $\checkmark$ & $\checkmark$ & $\checkmark$ & $\checkmark$ & & $\checkmark$ & $\mathrm{N}$ \\
\hline
\end{tabular}

Pazouki et al. conducted several studies on the scheduling of energy hubs, including a case study on an urban area in North-West Iran [21,57,58,61]. Economic scheduling resulted in the reduction of operational costs, an improvement in reliability, and a decrease in greenhouse gas emissions [21,57,58,61,68]. In another study, Moghaddaam et al. [65] presented a comprehensive profit-based model that allows the self-scheduling of energy hubs; the model was capable of adopting complex strategies, considering the cost of electricity and natural gas to maximize profit with a great accuracy and the potential of exchanging electricity with the grid. However, operation-scheduling always entails various sources of uncertainty. Vaccaro et al. [64] stated that these uncertainties mainly arise from the following: (i) unpredictable dynamics of energy prices, (ii) randomness of energy hub loads, and (iii) renewable energy converters. Nevertheless, the results obtained by Zidan et al. [68] showed significant enhancement in terms of emission reduction and reliability with the addition of renewable energy sources.

\subsubsection{Control}

Since hybrid energy systems are dynamic and susceptible to uncertainties, the need for communication and controller surfaces to ensure an effectively coordinated operation. These controllers are expected to adapt to changes in loads, based on the system dynamics and operational constraints [77]. Additionally, they keep these uncertainties within acceptable levels by using storage devices [78].

Intermittent renewable sources of energy are often termed energy vectors in the modeling of energy hubs [21,29]. However, as these sources of energy fail to provide a steady amount of energy 
throughout the year, the imbalance is either met by purchasing electricity off the grid or by backup generators [78]. Therefore, energy storage systems within hubs work as an asset that allows better control and, by extension, a more reliable, cost-effective energy system [77,78]. Approximately 50 of the publications reviewed modeled energy hubs with controllers and studied their effect on system performance. Several considered a model predictive control (MPC) approach, because MPCs allow flexible operations by self-adjusting their control definition based on controller objectives, operational constraints, and operating conditions. Table 4 demonstrates the relevant studies that focused on control technology used in integrated energy systems.

Table 4. List of research studies with a focus on control technology in energy hubs.

\begin{tabular}{|c|c|c|c|c|c|c|c|c|c|c|c|}
\hline \multirow{2}{*}{ Reference } & \multirow{2}{*}{ Paper Name } & \multicolumn{3}{|c|}{ Technology } & \multicolumn{5}{|c|}{ Energy Vectors } & \multirow{2}{*}{ Network } & \multirow{2}{*}{ Storag } \\
\hline & & CHP & Micro Solar & Wind & Elec & NG & Heat & Bio & $\mathrm{H}_{2}$ & & \\
\hline [79] & Arnold et al. (2008) - 1 & & & & $\checkmark$ & $\checkmark$ & $\checkmark$ & & & $\checkmark$ & $\mathrm{N}$ \\
\hline [80] & Adamek (2008) & $\checkmark$ & $\checkmark$ & $\checkmark$ & $\checkmark$ & $\checkmark$ & $\checkmark$ & $\checkmark$ & & $\checkmark$ & $\mathrm{N}$ \\
\hline [81] & Arnold et al. (2008) - 2 & $\checkmark$ & $\checkmark$ & $\checkmark$ & $\checkmark$ & $\checkmark$ & $\checkmark$ & & $\checkmark$ & $\checkmark$ & $\mathrm{N}$ \\
\hline [82] & Carradore and Turri (2009) & $\checkmark$ & & & $\checkmark$ & & $\checkmark$ & & & $\checkmark$ & $\mathrm{N}$ \\
\hline [83] & Ramirez-Elizondo and Paap (2009) & $\checkmark$ & & & $\checkmark$ & $\checkmark$ & $\checkmark$ & & & & $\mathrm{N}$ \\
\hline [77] & Arnold et al. (2009) & $\checkmark$ & & & $r$ & $\checkmark$ & $\checkmark$ & & & $\checkmark$ & $\mathrm{Y}$ \\
\hline [84] & Barsali et al. (2009) & $\checkmark$ & & & $\checkmark$ & $\checkmark$ & $\checkmark$ & & & & Y \\
\hline [85] & Carradore and Turri (2009) & $\checkmark$ & & & $r$ & $\checkmark$ & $\checkmark$ & & & $\checkmark$ & $\mathrm{Y}$ \\
\hline [86] & Negenborn et al. (2009) & $\checkmark$ & & & $v$ & $\checkmark$ & $\checkmark$ & & & $\checkmark$ & Y \\
\hline [13] & Galus et al. (2010) & $\checkmark$ & & $\checkmark$ & $v$ & $\checkmark$ & $\checkmark$ & & & $\checkmark$ & $\mathrm{Y}$ \\
\hline [14] & Ulbig et al. (2010) & & & & $\checkmark$ & $\checkmark$ & & & $\checkmark$ & & $\mathrm{Y}$ \\
\hline [87] & Arnold and Andersson (2010) & $\checkmark$ & $\checkmark$ & & $\checkmark$ & & & & & $\checkmark$ & $\mathrm{Y}$ \\
\hline [88] & Ramirez-Elizondo et al. (2010) & $\checkmark$ & & & $v$ & $\checkmark$ & $\checkmark$ & & & & $\mathrm{Y}$ \\
\hline [89] & Arnold et al (2010) & & & & $\boldsymbol{v}$ & $\checkmark$ & $\checkmark$ & & & $\checkmark$ & Y \\
\hline [90] & Velez (2010) & $\checkmark$ & & $\checkmark$ & $\checkmark$ & $\checkmark$ & $\checkmark$ & & & & $\mathrm{N}$ \\
\hline [91] & Almassalkhi and Hiskens (2011) - 1 & & & $\boldsymbol{v}$ & $\boldsymbol{v}$ & $\boldsymbol{v}$ & $\boldsymbol{v}$ & & & & Y \\
\hline [92] & Almassalkhi and Hiskens (2011) - 2 & $\checkmark$ & & $\checkmark$ & $\checkmark$ & $\checkmark$ & $\checkmark$ & & & $\checkmark$ & $\mathrm{Y}$ \\
\hline [93] & Parisio et al. (2011) & $\checkmark$ & & & $r$ & $\checkmark$ & $\checkmark$ & & $\checkmark$ & & $\mathrm{Y}$ \\
\hline [78] & Arnold and Andersson (2011) & $\checkmark$ & & & $\checkmark$ & $\checkmark$ & $\checkmark$ & & & $\checkmark$ & Y \\
\hline [94] & Sheikhi et al. (2011) & $\checkmark$ & & & $\checkmark$ & $\checkmark$ & $\checkmark$ & & & & $\mathrm{N}$ \\
\hline [95] & Arnold (2011) & $\checkmark$ & & & $\checkmark$ & $\checkmark$ & $\checkmark$ & & & $\checkmark$ & Y \\
\hline [96] & Velez (2011) & $\checkmark$ & & $\checkmark$ & $\checkmark$ & $\checkmark$ & $\checkmark$ & & & & Y \\
\hline [97] & Ulbig et al. (2011) & $\checkmark$ & & $\checkmark$ & $\checkmark$ & $\checkmark$ & $\checkmark$ & & & $\checkmark$ & $\mathrm{Y}$ \\
\hline [98] & Akgun and Cakmakci (2012) & $\checkmark$ & & & $\checkmark$ & $\checkmark$ & $\checkmark$ & & & & Y \\
\hline [19] & Galus et al. (2012) & & & & $r$ & $\checkmark$ & $\checkmark$ & & & $\checkmark$ & $\mathrm{Y}$ \\
\hline [99] & Pazouki et al. (2013) & $\checkmark$ & $\checkmark$ & $\checkmark$ & $\checkmark$ & $\checkmark$ & $\checkmark$ & & & & $\mathrm{Y}$ \\
\hline [59] & Haghifam et al. (2013) & $\checkmark$ & & $v$ & $v$ & $\checkmark$ & $\checkmark$ & & & & $\mathrm{Y}$ \\
\hline [100] & Almassalkhi (2013) & & & $\checkmark$ & $\checkmark$ & $\checkmark$ & $\checkmark$ & & & $\checkmark$ & $\mathrm{Y}$ \\
\hline [101] & Yu et al. (2014) & $\checkmark$ & & & $\checkmark$ & $\checkmark$ & $\checkmark$ & & & & $\mathrm{Y}$ \\
\hline [102] & Moeini-Aghtaie et al. (2014) & $\checkmark$ & & $\checkmark$ & $\checkmark$ & $\checkmark$ & $\checkmark$ & & & $\checkmark$ & $\mathrm{N}$ \\
\hline [103] & Soroudi et al. (2014) & $\checkmark$ & & $\checkmark$ & $v$ & $\checkmark$ & & & & & $\mathrm{Y}$ \\
\hline [104] & Kampouropoulos et al. (2014) & $\checkmark$ & & & $\checkmark$ & $\checkmark$ & $\checkmark$ & & & & $\mathrm{N}$ \\
\hline [105] & S. Moazeni et al. (2015) & & $\checkmark$ & $\checkmark$ & $v$ & & & & & & $\mathrm{Y}$ \\
\hline [106] & Skarvelis-Kazakos et al. (2015) & $\checkmark$ & & & $\checkmark$ & $\checkmark$ & $\checkmark$ & & $\checkmark$ & $\checkmark$ & $\mathrm{Y}$ \\
\hline [107] & Moeini-Aghtaie et al. (2015) & $\checkmark$ & & $\checkmark$ & 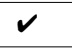 & $\checkmark$ & $\checkmark$ & & & & $\mathrm{Y}$ \\
\hline [108] & Mitchell and Skarvelis-Kazakos (2015) & $\checkmark$ & & & $v$ & & $\checkmark$ & $\checkmark$ & & & $\mathrm{N}$ \\
\hline [109] & Rastegar et al. (2015) & $\checkmark$ & & & $\boldsymbol{v}$ & $\checkmark$ & $\boldsymbol{v}$ & & & & Y \\
\hline [110] & Salimi et al. (2015) & $v$ & & & $\boldsymbol{v}$ & $\boldsymbol{v}$ & $\boldsymbol{v}$ & & & $\boldsymbol{v}$ & $\mathrm{Y}$ \\
\hline
\end{tabular}


Table 4. Cont.

\begin{tabular}{|c|c|c|c|c|c|c|c|c|c|c|c|c|}
\hline \multirow{2}{*}{ Reference } & \multirow{2}{*}{ Paper Name } & \multicolumn{4}{|c|}{ Technology } & \multicolumn{5}{|c|}{ Energy Vectors } & \multirow{2}{*}{ Network } & \multirow{2}{*}{ Storage } \\
\hline & & CHP & Micro & Solar & Wind & Elec & NG & Heat & Bio & $\mathbf{H}_{2}$ & & \\
\hline [62] & Xu et al. (2015) & $\checkmark$ & $\checkmark$ & $\checkmark$ & & $\checkmark$ & $\checkmark$ & $\checkmark$ & & & & $\mathrm{Y}$ \\
\hline [111] & Skarvelis-Kazakos et al. (2016) & $\checkmark$ & & $\checkmark$ & $\checkmark$ & $\checkmark$ & $\checkmark$ & $\checkmark$ & & & $\checkmark$ & $\mathrm{Y}$ \\
\hline [112] & Teng et al. (2016) & $\boldsymbol{V}$ & & $\checkmark$ & $\checkmark$ & $\boldsymbol{V}$ & $\checkmark$ & $\boldsymbol{V}$ & & & & $\mathrm{Y}$ \\
\hline [114] & Hernández-Hernández et al. (2017) & & $\checkmark$ & $\checkmark$ & & $\checkmark$ & & & & & & $\mathrm{Y}$ \\
\hline$[115]$ & Liu et al. (2017) & $\checkmark$ & & & & $\checkmark$ & $\checkmark$ & $\checkmark$ & & & & $\mathrm{Y}$ \\
\hline$[116]$ & Hernández-Hernández et al. (2017) & & $\checkmark$ & $\checkmark$ & & $\boldsymbol{V}$ & & $\checkmark$ & & & & $\mathrm{Y}$ \\
\hline$[117,118]$ & Baghaee et al. (2017) & & $\checkmark$ & $\checkmark$ & $\checkmark$ & $\checkmark$ & & & & $\checkmark$ & & $\mathrm{Y}$ \\
\hline
\end{tabular}

Arnold et al. [77] applied the MPC approach to a network of energy hubs and observed a decrease in the total operational costs, coupled with an increase in the computational efforts with longer prediction intervals. Almassalkhi [100] implemented a receding-model predictive controller (RHMPC) for the transmission of electricity involving renewables and storage systems. Del Real et al. [24] adopted a Lagrange-based distributed model predictive control (DMPC) framework that aids in the economic dispatch of smart grids based on the networks of energy hubs.

Existing literature on energy hub operation management often assumes a perfect forecast of prices and different types of demand $[78,119]$. Hence, uncertainty and stochastic conditions of these inputs over time are not usually accounted for when looking for optimal operation decisions. When all exogenous input variables such as demands and prices are assumed to be certain (which can be the case if the uncertainties are hedged by contracts such as forward contracts for prices), the optimal control of energy hubs can be computed by deterministic optimization, such as mixed integer linear/non-linear programming (MILP/MINLP) models. The authors of [120] considered an energy hub with a variety of electricity, heat and hydrogen generating plants, and energy storage devices to serve uncertain electricity and heat loads over a finite time horizon, in the presence of real-time uncertain prices. They modeled uncertainties in loads and prices by stochastic processes and developed a stochastic dynamic programming formulation for the energy hub operation management problem. This optimization model is aimed at obtaining a sequence of decision rules for the entire time horizon that adapts to the realized information at any time step. In this closed-loop optimization approach, decisions at any time step are readily derived by applying the decision rule for the system state, e.g., storage levels, and exogenous variables, such as demands and prices, at that time step. For systems involving multiple storage units and exposed to various sources of uncertainty, which is often the case for energy hubs, the dimension of the state variable is too high to solve the resulting dynamic programming optimization exactly. In this context, approximate dynamic programming (ADP) approaches seem appropriate. However, ADP approaches are not amenable to risk-averse considerations by the energy hub manager/controller. The importance of risk considerations when managing an energy system in the presence of uncertainty is discussed in [105]. Therefore, to compute a risk-averse dynamic energy hub operation management solution in [120], an ADP approach based on direct policy search and cost function approximations, proposed in [121,122], was adopted. This framework is capable of handling various operational and physical constraints, as well as a risk-averse objective function. The authors of [123] also proposed a new modeling approach for minimum uptime/downtime constraints of some assets within their proposed dynamic optimization framework, when the traditional methods for modeling these constraints fail.

\subsubsection{Assessment}

The assessment of flexible factors, such as hourly solar irradiation or wind speed within an energy hub, is crucial in the design and operation of processes [124]. Based on the outcome, scheduling may 
be carried out, and controllers may be added to a particular energy system. Upon implementation, the system can be further evaluated in terms of performance, economic, and environmental feasibility. Specifically, it may aid in examining the individual effects of each variation introduced into the system.

An assessment framework designed by Fabrizio et al. [124] utilized an hourly model to assess the performance of an entire system, and the integrated utilization of energy resources. Rather than modeling the dynamic nature of the system, they observed the differences between two successive states of operation under steady-state conditions [124]. With this data, they determined the layout and sizing of energy converters, as well as other components. Table 5 presents the literature in this field.

Table 5. Evaluation studies conducted on multi-energy carrier systems.

\begin{tabular}{|c|c|c|c|c|c|c|c|c|c|c|c|c|c|}
\hline \multirow{2}{*}{ Reference } & \multirow{2}{*}{ Paper } & \multicolumn{5}{|c|}{ Technology } & \multicolumn{5}{|c|}{ Energy Vectors } & \multirow{2}{*}{ Network } & \multirow{2}{*}{ Storage } \\
\hline & & CHP & Micro & Solar & Wind & Hydro & Elec & NG & Heat & Bio & $\mathrm{H}_{2}$ & & \\
\hline$[124]$ & Fabrizio et al. (2009) & & & $\checkmark$ & & & $\checkmark$ & $\checkmark$ & $\checkmark$ & & & & $\mathrm{Y}$ \\
\hline [125] & $\begin{array}{l}\text { Martinez-Mares and Fuerte-Esquivel } \\
\text { (2012) }\end{array}$ & & & & & & $\boldsymbol{v}$ & $\checkmark$ & & & & $\checkmark$ & $\mathrm{N}$ \\
\hline [126] & Anderson et al. (2013) & $\checkmark$ & & $\checkmark$ & $\checkmark$ & & $v$ & $v$ & $v$ & & & $v$ & $\mathrm{~N}$ \\
\hline [127] & $\begin{array}{l}\text { Martinez-Mares and Fuerte-Esquivel } \\
\text { (2013) }\end{array}$ & & & & $\checkmark$ & $\checkmark$ & $\boldsymbol{v}$ & $\checkmark$ & $\checkmark$ & & & & $\mathrm{N}$ \\
\hline [128] & Giaouris et al. (2013) & & $\checkmark$ & $\checkmark$ & $\checkmark$ & & & & & & $\checkmark$ & $\checkmark$ & $\mathrm{Y}$ \\
\hline [129] & Orehounig et al. (2014) & & & $\checkmark$ & & $\checkmark$ & $\checkmark$ & & $\checkmark$ & $\checkmark$ & & & $\mathrm{N}$ \\
\hline [130] & Xu et al. (2015) & $\checkmark$ & 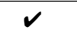 & $\checkmark$ & $\checkmark$ & & $\checkmark$ & $\checkmark$ & $\checkmark$ & $\checkmark$ & $\checkmark$ & $\checkmark$ & $\mathrm{N}$ \\
\hline [131] & Perera et al. (2015) & & & $\checkmark$ & $\checkmark$ & & $\checkmark$ & $\checkmark$ & $\checkmark$ & & & $\checkmark$ & $\mathrm{Y}$ \\
\hline [132] & Liu and Mancarella (2016) & $\checkmark$ & & & & & $\checkmark$ & $\boldsymbol{v}$ & $\checkmark$ & & & & $\mathrm{N}$ \\
\hline [133] & Shabanpour-Haghighi and Seifi (2016) & $\checkmark$ & & & & & $\checkmark$ & $\boldsymbol{v}$ & $\checkmark$ & & & $\checkmark$ & $\mathrm{N}$ \\
\hline [134] & Pazouki and Haghifam (2016) & $\checkmark$ & & & & & $\checkmark$ & $\checkmark$ & $\checkmark$ & & & & $\mathrm{N}$ \\
\hline [135] & Shariatkhah et al. (2016) & $\checkmark$ & & & & & $\boldsymbol{v}$ & $\boldsymbol{v}$ & $\boldsymbol{v}$ & & & & $\mathrm{N}$ \\
\hline [136] & Abeysekera (2016) & $\boldsymbol{v}$ & & & & & $\boldsymbol{v}$ & $\boldsymbol{v}$ & $\checkmark$ & & & & $\mathrm{Y}$ \\
\hline [137] & Moeini-Aghtaie et al. (2017) & $\checkmark$ & & & $\boldsymbol{V}$ & & $\boldsymbol{V}$ & $\boldsymbol{V}$ & $\boldsymbol{v}$ & & & & $\mathrm{Y}$ \\
\hline [138] & Ma et al. (2017) & $\checkmark$ & $\checkmark$ & $\checkmark$ & $\checkmark$ & & $\checkmark$ & $\checkmark$ & $\checkmark$ & & & & $\mathrm{Y}$ \\
\hline [139] & Morvaj et al. (2017) & $\checkmark$ & & $\checkmark$ & & & $\checkmark$ & $\checkmark$ & $\checkmark$ & & & & $\mathrm{Y}$ \\
\hline
\end{tabular}

\subsection{Economic and Environmental Considerations}

Economic improvement and greenhouse gas mitigation are the significant intended outcomes of future energy systems. The focus of several studies in the literature surveyed was an evaluation of an energy hub system based on economic and environmental aspects. The energy systems were modeled using the energy hub approach and the results were then compared to previous case studies or present reality.

\subsubsection{Economics and Financials}

In the economic assessment of multiple energy carrier systems, the cost of available energy resources is one of the focal points of the study. Feasibility studies can be carried out to determine the viability of using a particular energy source, with or without an energy hub framework. On the other hand, the economic impact of a particular schedule, controller, or any other adjustment can be observed. In addition, models have been developed to devise energy systems economically whilst considering changes in energy prices and the future energy demand. Many of these studies have been listed in Table 6. 
Table 6. List of studies that include economic considerations.

\begin{tabular}{|c|c|c|c|c|c|c|c|c|c|c|c|c|}
\hline \multirow{2}{*}{ Reference } & \multirow{2}{*}{ Paper Name } & \multicolumn{4}{|c|}{ Technology } & \multicolumn{5}{|c|}{ Energy Vectors } & \multirow{2}{*}{ Network } & \multirow{2}{*}{ Storage } \\
\hline & & $\mathrm{CHP}$ & Solar & Wind & Hydro & Elec & NG & Heat & Bio & $\mathbf{H}_{2}$ & & \\
\hline [140] & Egli (2007) & & & & & $\checkmark$ & $\checkmark$ & $v$ & & & $\checkmark$ & $\mathrm{N}$ \\
\hline [81] & Arnold et al. (2008) & $\checkmark$ & $\checkmark$ & $\checkmark$ & & $\checkmark$ & $\checkmark$ & $\checkmark$ & & $r$ & $\checkmark$ & $\mathrm{N}$ \\
\hline [141] & Iggland and Kienzle (2008) & & $\checkmark$ & $\checkmark$ & $\checkmark$ & $\checkmark$ & $\checkmark$ & $\checkmark$ & $\checkmark$ & & $\checkmark$ & $\mathrm{N}$ \\
\hline [142] & Kienzle and Andersson (2014) & $\checkmark$ & & & & $\checkmark$ & $\checkmark$ & $\checkmark$ & $\checkmark$ & & & $\mathrm{N}$ \\
\hline [22] & Fabrizio et al. (2009) & $\checkmark$ & $\checkmark$ & $\checkmark$ & $\checkmark$ & $\checkmark$ & $\checkmark$ & $\checkmark$ & $\checkmark$ & $\boldsymbol{v}$ & $\checkmark$ & $\mathrm{N}$ \\
\hline [143] & Schulze and Del Granado (2009) & $\checkmark$ & $\checkmark$ & $\checkmark$ & & $\checkmark$ & $\checkmark$ & $\checkmark$ & $\checkmark$ & & $\checkmark$ & $\mathrm{N}$ \\
\hline [144] & Kienzle (2010) & $\checkmark$ & & & & $\checkmark$ & $\checkmark$ & $\checkmark$ & $\checkmark$ & & $\checkmark$ & $\mathrm{Y}$ \\
\hline [145] & Kienzle and Andersson (2010) & $\checkmark$ & & & & $\checkmark$ & $\checkmark$ & $\checkmark$ & & & $\checkmark$ & $\mathrm{Y}$ \\
\hline [146] & Shireen and Patel (2010) & & $\checkmark$ & & & $\checkmark$ & & & & & & $\mathrm{Y}$ \\
\hline [147] & Favre-Perrod et al. (2010) & & & & & $\checkmark$ & $\checkmark$ & & & & $\checkmark$ & $\mathrm{N}$ \\
\hline [148] & Schulze et al. (2010) & & & & & $\checkmark$ & & $\checkmark$ & & & $\checkmark$ & $\mathrm{Y}$ \\
\hline [149] & Zafra-Cabeza et al. (2010) & $\checkmark$ & & $\checkmark$ & & $\checkmark$ & & $\checkmark$ & & $r$ & & $\mathrm{Y}$ \\
\hline [150] & Kienzle et al. (2011) & $\checkmark$ & & & & $\checkmark$ & $\checkmark$ & $\checkmark$ & $\checkmark$ & & & $\mathrm{Y}$ \\
\hline [151] & Ranjbar et al. (2011) & $\checkmark$ & & & & $\checkmark$ & $\checkmark$ & $\checkmark$ & & & & $\mathrm{Y}$ \\
\hline [152] & Fabrizio (2011) & $\checkmark$ & $\checkmark$ & & & $\checkmark$ & $\checkmark$ & $\checkmark$ & & & & $\mathrm{N}$ \\
\hline [119] & Sheikhi et al. (2012) & $\checkmark$ & & & & $\checkmark$ & $\checkmark$ & $\checkmark$ & & & & $\mathrm{Y}$ \\
\hline [153] & Bahrami and Safe (2013) & $\checkmark$ & & & & $\checkmark$ & $\checkmark$ & $\checkmark$ & & & & $\mathrm{Y}$ \\
\hline [21] & Pazouki et al. (2013) & $\checkmark$ & & $\checkmark$ & & $\checkmark$ & $\checkmark$ & $\checkmark$ & & & & $\mathrm{Y}$ \\
\hline [154] & Adamek et al. (2014) & $\checkmark$ & & & & $\checkmark$ & $\checkmark$ & $\checkmark$ & & & $\checkmark$ & $\mathrm{Y}$ \\
\hline [102] & Moeini-Aghtaie et al. (2014) & $\checkmark$ & & $\checkmark$ & & $\checkmark$ & $\checkmark$ & $\checkmark$ & & & $\checkmark$ & $\mathrm{N}$ \\
\hline [155] & Le Blond et al. (2014) & & $\checkmark$ & & & $\checkmark$ & $\checkmark$ & $\checkmark$ & & & & $\mathrm{Y}$ \\
\hline [27] & Rayati et al. (2015) & $\checkmark$ & & & & $\checkmark$ & $\checkmark$ & $\checkmark$ & & & & $\mathrm{Y}$ \\
\hline [156] & Maroufmashat et al. (2015) & $v$ & & & & $\checkmark$ & $\checkmark$ & $\checkmark$ & & & $\checkmark$ & $\mathrm{Y}$ \\
\hline [157] & Kamyab and Bahrami (2016) & $\checkmark$ & $\checkmark$ & & & $\checkmark$ & $\checkmark$ & $\checkmark$ & & & $\checkmark$ & $\mathrm{Y}$ \\
\hline [158] & Moghaddam et al. (2016) & $v$ & & & & $\checkmark$ & $\checkmark$ & $\checkmark$ & & & $\checkmark$ & $\mathrm{N}$ \\
\hline [159] & Facchinetti and Sulzer (2016) & & & & & & & & & & & $\mathrm{N}$ \\
\hline [160] & Sheikhi et al. (2016) & $\checkmark$ & & & & $\checkmark$ & $\checkmark$ & $\checkmark$ & & & & $\mathrm{Y}$ \\
\hline [161] & Beigvand et al. (2017) & $\checkmark$ & & & & $\checkmark$ & $\checkmark$ & $\checkmark$ & & & $\checkmark$ & $\mathrm{N}$ \\
\hline [162] & Majidi et al. (2017) & $v$ & & $\checkmark$ & $\checkmark$ & $\checkmark$ & $\checkmark$ & $v$ & & & & $\mathrm{Y}$ \\
\hline [163] & Li et al. (2017) & $\checkmark$ & $\checkmark$ & & & $\checkmark$ & $\checkmark$ & $\checkmark$ & & & & $\mathrm{Y}$ \\
\hline [164] & Rafea (2017) & $v$ & & $\checkmark$ & & $\checkmark$ & $\checkmark$ & $\checkmark$ & & $v$ & & $\mathrm{Y}$ \\
\hline [165] & Sharif et al. (2014) & $\checkmark$ & $\checkmark$ & $\checkmark$ & & $\checkmark$ & $\checkmark$ & $\checkmark$ & $\checkmark$ & & & $\mathrm{Y}$ \\
\hline
\end{tabular}

Fabrizio et al. [22] carried out research to establish economic and environmental objectives and investigated their trade-offs. In another study by Fabrizio, the economic feasibility of applying the energy hub framework to health-care facilities was investigated in multiple scenarios. Schulze and Del Granado [143] concluded that feed-in tariffs to promote renewable energy were an effective methodology to increase overall benefits while satisfying the energy demand [140-143]. A study by Barsali et al. [84] investigated the viability of energy storage systems based on energy tariff changes across different hours of the day.

Kienzle [144] developed a model to optimize a portfolio of energy investments, applying the mean variance portfolio theory. He [142] also presented a method of evaluating energy hubs under uncertainty. Instead of utilizing historical price data as the basis for financial analysis, a Monte Carlo approach was used to account for policy and technology changes. Kienzle et al. [150] extended the Monte Carlo approach to incorporate demand-side management (DSM) of loads.

Maniyali et al. [166] formulated an energy hub model which incorporates nuclear energy and hydrogen storage, in addition to wind, solar, and biomass energy. Detailed analysis was conducted on the minimal cost scenario, minimal emissions scenario, and hydrogen economy scenario. 
Sharif et al. [165] adapted the energy hub model to use natural gas as the main energy source to be supplemented by wind and solar energy as well as hydrogen energy storage. They developed a model in General Algebraic Modeling Software (GAMS) and considered three scenarios: a baseline single energy carrier scenario, a multi-energy carrier scenario, and a multi-energy carrier scenario with energy storage. The third scenario produced both the lowest cost and emissions.

\subsubsection{Emissions}

In recent years, aside from being more cost-competitive, renewable energy systems have also become technically feasible for small domestic applications, such as solar charging stations and thermal desalination processes $[167,168]$. Many research studies carried out the integration of renewable energy sources (RES) with the existing power grid and electricity markets [169]. Another major advantage of using renewables over non-renewables is the immense reduction of GHGs and water pollution [170]. Despite a study which argued that renewable energy sources, specifically hydropower, are not entirely "clean" and do have associated environmental impacts [171], the positive impact of renewables on the environment is a force to be reckoned with. Yet, according to statistics reported by the International Energy Agency (IEA) in 1998, fossil-based power generation systems emitted roughly 60-100 times more GHG emissions per kWh than those of renewables [172]. Several studies couple techno-economic feasibility research with the study of the environmental impacts of multiple energy systems. Some of them are given in Table 7.

Table 7. List of research papers that include environmental considerations.

\begin{tabular}{|c|c|c|c|c|c|c|c|c|c|c|c|c|}
\hline \multirow{2}{*}{ Reference } & \multirow{2}{*}{ Paper name } & \multicolumn{4}{|c|}{ Technology } & \multicolumn{5}{|c|}{ Energy Vectors } & \multirow{2}{*}{ Network } & \multirow{2}{*}{ Storage } \\
\hline & & CHP & Solar & Wind & Hydro & Elec & NG & Heat & Bio & $\mathrm{H}_{2}$ & & \\
\hline [173] & Chicco and Mancarella (2008) & $\checkmark$ & & & & & & & & & & $\mathrm{N}$ \\
\hline [22] & Fabrizio et al. (2009) & $\checkmark$ & $v$ & $v$ & $\checkmark$ & $\checkmark$ & $\checkmark$ & $\checkmark$ & $v$ & $v$ & $\checkmark$ & $\mathrm{N}$ \\
\hline [174] & Galus et al. (2009) & & & & & $\checkmark$ & $\checkmark$ & $\checkmark$ & & & $\checkmark$ & $\mathrm{N}$ \\
\hline [23] & Dai and Wang (2009) & $\checkmark$ & & & & $\checkmark$ & $\checkmark$ & $\checkmark$ & & & $\checkmark$ & $\mathrm{N}$ \\
\hline [155] & Le Blond et al. (2014) & & $v$ & & & $\checkmark$ & $\checkmark$ & $\checkmark$ & & & & $\mathrm{Y}$ \\
\hline [175] & Orehounig et al. (2014) & $\checkmark$ & $v$ & & $\checkmark$ & $\checkmark$ & $\checkmark$ & $\checkmark$ & $v$ & & $\checkmark$ & $\mathrm{Y}$ \\
\hline [156] & Maroufmashat et al. (2015) & $\checkmark$ & & & & $\checkmark$ & $\checkmark$ & $\checkmark$ & & & $\checkmark$ & $\mathrm{Y}$ \\
\hline [176] & LI et al. (2016) & $\checkmark$ & $\checkmark$ & $v$ & & $\checkmark$ & $\checkmark$ & $\checkmark$ & & & & $\mathrm{Y}$ \\
\hline [177] & Fuentes-Cortés et al. (2016) & $\checkmark$ & & & & $\checkmark$ & $\checkmark$ & $\checkmark$ & $v$ & & & $\mathrm{Y}$ \\
\hline [34] & Phdungsilp and Martinac (2016) & & & & & & & & & & & - \\
\hline [139] & Morvaj et al. (2017) & $\checkmark$ & $v$ & & & $\checkmark$ & $\checkmark$ & $\checkmark$ & & & & $\mathrm{Y}$ \\
\hline [162] & Majidi et al. (2017) & $\checkmark$ & & $v$ & $\checkmark$ & $\checkmark$ & $\checkmark$ & $\checkmark$ & & & & $\mathrm{Y}$ \\
\hline [164] & Rafea (2017) & $\checkmark$ & & $v$ & & $\checkmark$ & $\checkmark$ & $\checkmark$ & & $\checkmark$ & & $\mathrm{Y}$ \\
\hline
\end{tabular}

Energy hubs can reduce emissions related to energy production and transmission since they can integrate multiple renewable energy carriers. Orehounig et al. [175] investigated the integration of renewable energies for a small village using the energy hub concept. They conducted further studies regarding the implementation of energy systems in the same village, including retrofitting buildings and neighboring. Similar to their previous study, they simulated a set of scenarios and found that the best performing scenario had an $86 \%$ reduction in carbon emissions [175].

Chicco and Mancarella focused on the energy and environmental evaluation of poly-generation systems, powered by natural gas [173]. An indicator was developed to assess the energy systems according to environmental factors. Moreover, it can aid policy makers to cultivate financially-motivated tactics to help mitigate $\mathrm{CO}_{2}$ emissions [173]. Galus et al. [174] designed a framework for plug-in hybrid electric vehicles (PHEVs), using the energy hub approach to forecast a region-wide $\mathrm{CO}_{2}$ emission decrease.

Del Real et al. [24] studied the power dispatch of energy hub networks by considering the cost of environmental impacts as part of an objective function. Morvaj et al. [127] investigated the impact 
on energy systems when mitigating carbon emissions from the electricity grid [136-139]. Several scenarios were simulated using the energy hub framework and a Pareto front was constructed for each. Increasing the share of renewables in the generation of power decreases carbon emissions, but at a financial cost [139].

\subsection{Applications}

The energy hub approach has opened up a wide spectrum of possibilities for the integration of various energy loads. Based on the literature reviewed, this approach has been perceived as one of the significant methods towards future energy systems. Moreover, the transition to future energy systems involves utilizing distributed energy resources (DERs), and green or zero-emission vehicles (ZEV), as well as building a hydrogen economy. A "hydrogen economy" is where hydrogen is generated via emission-free nuclear and renewable technologies and then used as an engy vector to store or distribute it to end-users, especially for power transportation applications. Many studies have established the application of energy hubs. During the inception of the energy hub approach, Geidl and Andersson carried out an example that included the proposed planning, scheduling, and security analysis for the application of energy hubs [178]. However, the distributed energy resources, electric vehicles, and hydrogen economy are the major research interests at present.

\subsubsection{Distributed Energy Resources (DERs)}

Distributed energy resources commonly referred to as decentralized power generation systems, as opposed to centralized power plants, are often located in remote or "off grid" areas, providing energy to a specific region. These include, but are not limited to, microgrids, diesel generators, solar panels, wind turbines, combined heat and power (CHP), micro turbines, and energy storage systems [179]. With the methodology proposed by Geidl and Anderson, DER can be easily modeled using the energy hub approach [6]. It is reflected by the tables of research studies presented in this paper along with the renewable energy (RE) vectors.

In a study, Hemmes et al. [180] demonstrated five applications of energy hubs as distributed energy systems, including multiple energy carriers with CHP, the production of hydrogen, re-electrification by fuel cells with and without fluctuating renewable energy, and the integration of fuel cells into a natural gas network. Schulze et al. [181] applied the energy hub model with the aim of optimizing energy flow, using renewables. Franziska applied the energy hub approach to examine the optimal power supply for a larger region with an increasing renewable demand [80]. A multilevel model was introduced when determining the optimal power supply strategy for an area with varying power generation levels and various energy carriers. This study considered the impact of renewable energy power plants and storage systems of various sizes and costs, deciding which energy conversion and storage technologies to employ and where to place them, whilst minimizing the dependency on centralized power plants [80]. Maroufmashat et al. [182] developed an energy hub network, modeling a distributed energy system, considering combined heat and power (CHP) systems and solar energy. That study has shown that the proposed energy network has the ability to reduce the cost due to its potential to mitigate carbon emissions.

Del Real [183] performed an optimization study on a solar-hydrogen energy system, conceptualized through the energy hub approach and used for residential purposes. The model was able to determine the optimal power flow and hydrogen storage through the year, considering seasonal changes [183]. Anastasiadis et al. [184] examined the power losses in low-voltage micro-grids using energy hubs. The highest annual energy losses were observed in scenarios where no DER were considered. Moreover, independently operated DER, including wind turbines, solar photovoltaic (PV), and combined heat and power (CHP) technologies, showed about 59\% less annual power loss than the former case (i.e., no DES) $[183,184]$.

In a review study, Chicco and Mancarella described energy hubs as one of the emerging approaches towards decentralized and multi-generation systems, in addition to micro-grids and virtual power 
plants [36]. On the contrary, Buhler studied the integration of renewables into these energy systems and discussed how the energy hub approach should be used to enhance virtual power plants and micro-grids [29]. In a study conducted by Schule and Crespo Del Granado, three storage systems with intermittent renewable energy sources were optimized using the energy hub model. Moreover, an model-based optimization tool was developed to help reduce the computation time [185]. Robertson et al. developed a simulation tool called hybrid energy system analysis (HESA), based on the energy hub model, to investigate the impact of DER systems of various levels and sizes on the existing energy infrastructure [186].

\subsubsection{Plug-in Hybrid Electric Vehicles and Battery Electric Vehicles}

Several studies have been conducted that have demonstrated the modeling and optimization research performed on plug-in hybrid electric vehicles (PHEVs) and battery electric vehicles (BEVs), charging infrastructure, and integration into the current system, using energy hubs. Note that since BEVs and PHEVs draw electrical power from the grid or energy hub and store it on-board, the vehicle can be used in a grid-to-vehicle (G2V) or vehicle-to-grid (V2G) model. Table 8 shows many of these studies, along with the technology and energy vectors considered within them [187].

Table 8. List of research studies conducted on electric vehicles and infrastructure sorted chronologically.

\begin{tabular}{|c|c|c|c|c|c|c|c|c|c|c|c|}
\hline \multirow{2}{*}{ Reference } & \multirow{2}{*}{ Paper Name } & \multicolumn{4}{|c|}{ Technology } & \multicolumn{4}{|c|}{ Energy Vectors } & \multirow{2}{*}{ Network } & \multirow{2}{*}{ Storage } \\
\hline & & CHP & Micro & Solar & Wind & Elec & NG & Heat & $\mathrm{H}_{2}$ & & \\
\hline [188] & Galus and Andersson (2008) & $\checkmark$ & & & & $\checkmark$ & $\checkmark$ & $\checkmark$ & & $\checkmark$ & $\mathrm{N}$ \\
\hline [189] & Galus and Andersson (2009) - 1 & & & & & $\checkmark$ & $\checkmark$ & & $\checkmark$ & & $\mathrm{Y}$ \\
\hline [55] & Galus and Andersson (2009) - 2 & $\checkmark$ & & & & $\checkmark$ & $\checkmark$ & $\checkmark$ & & $\checkmark$ & $\mathrm{Y}$ \\
\hline [174] & Galus et al. (2009) & & & & & $\boldsymbol{V}$ & $\checkmark$ & $\checkmark$ & & $\checkmark$ & $\mathrm{N}$ \\
\hline [190] & Acha et al. (2009) & $\checkmark$ & & & & $\checkmark$ & $\checkmark$ & & & $\checkmark$ & $\mathrm{N}$ \\
\hline [191] & Syed et al. (2010) & & & & & $\checkmark$ & & & $\checkmark$ & & $\mathrm{Y}$ \\
\hline [13] & Galus et al. (2010) & $\checkmark$ & & & $\checkmark$ & $\checkmark$ & $\checkmark$ & $\checkmark$ & & $\checkmark$ & $\mathrm{Y}$ \\
\hline [14] & Ulbig et al. (2010) & & & & & $\checkmark$ & $\checkmark$ & & $\checkmark$ & & $\mathrm{Y}$ \\
\hline [146] & Shireen and Patel (2010) & & & $\checkmark$ & & $\checkmark$ & & & & & Y \\
\hline [192] & Schulze and Riveros (2010) & & & & & $\checkmark$ & & & & $\checkmark$ & $\mathrm{N}$ \\
\hline [193] & Syed (2011) & & & & $\checkmark$ & $\checkmark$ & & $\checkmark$ & $\checkmark$ & & $\mathrm{Y}$ \\
\hline [194] & Whitefoot (2012) & & $\checkmark$ & $\checkmark$ & & $\checkmark$ & & & & & Y \\
\hline [19] & Galus et al. (2012) & & & & & $\checkmark$ & $\checkmark$ & $\checkmark$ & & $\checkmark$ & $\mathrm{Y}$ \\
\hline [59] & Haghifam et al. (2013) & $\checkmark$ & & & $\checkmark$ & $\checkmark$ & $\checkmark$ & $\checkmark$ & & & $\mathrm{Y}$ \\
\hline [195] & Waraich et al. (2013) & $\checkmark$ & & & & $\checkmark$ & $\checkmark$ & & & $\checkmark$ & $\mathrm{Y}$ \\
\hline [60] & Rastegar and Fotuhi-Firuzabad (2014) & $\checkmark$ & & & & $\checkmark$ & $\checkmark$ & $\checkmark$ & & & Y \\
\hline [196] & Damavandi et al. (2014) & $\checkmark$ & & & & $\checkmark$ & $\checkmark$ & $\checkmark$ & & & $\mathrm{Y}$ \\
\hline [107] & Moeini-Aghtaie et al. (2015) & $\checkmark$ & & & $\checkmark$ & $\checkmark$ & $\checkmark$ & $\checkmark$ & & & $\mathrm{Y}$ \\
\hline [197] & Rastegar and Fotuhi-Firuzabad (2015) & $\checkmark$ & & $\checkmark$ & $\checkmark$ & $\checkmark$ & $\checkmark$ & $\checkmark$ & & & $\mathrm{Y}$ \\
\hline [67] & Morvaj et al. (2016) & $\boldsymbol{V}$ & & & & $\boldsymbol{V}$ & $\checkmark$ & $\boldsymbol{V}$ & & $\boldsymbol{V}$ & $\mathrm{Y}$ \\
\hline [198] & Yazdani-Damavandi et al. (2016) & $\checkmark$ & & & $\checkmark$ & $\checkmark$ & $\checkmark$ & $\boldsymbol{V}$ & $\checkmark$ & & $\mathrm{Y}$ \\
\hline [199] & Neyestani (2016) & $\checkmark$ & & & $\checkmark$ & $\checkmark$ & $\checkmark$ & $\checkmark$ & & & $\mathrm{Y}$ \\
\hline
\end{tabular}

Galus and Andersson applied the methodology to demonstrate the potential of the energy hub approach for the implementation of PHEVs in different applications $[55,189]$. Different operating states, such as driving, charging, refueling, and regulation services of the electricity network, can be easily modeled using the proposed framework [189]. In addition to easily extending the model with various other architectures, the energy hub model allows extensive space for optimization.

Prior to implementing PHEVs on a large scale, a reliable infrastructure needs to be provided. Andrade et al. modeled a parking lot that served as a charging station for electric vehicles [200]. Three different scenarios (i.e. early morning, morning, and afternoon) were examined to analyze power flow in the electric parking lot, using MATLAB Simulink. It was observed that the electricity consumption by the electric vehicles was much higher than the daily peak demand. Therefore, a bigger transformer 
and an effective energy management system were required [200]. Another study, by Damavandi et al., considered the parking lot as a storage system [196]. The results indicated that the operation of energy hubs was very flexible and allowed changes to meet the energy demand [196]. In addition to parking lots, Rastegar and Fotuhi-Firuzabad were able to determine optimal charge scheduling for PHEVs at home, using the energy hub model, based on time-differentiated electricity pricing [60].

The integration of PHEVs with a smart grid, modeled by four energy hubs, was studied by Waraich et al. [200]. The energy demand of PHEVs was simulated using an agent-based traffic demand model, and various charging policies were tested. The proposed approach was successful in determining whether a particular energy infrastructure was capable of handling a certain penetration of PHEVs [200]. Using the energy hub approach, Morvaj et al. [67] were able to successfully develop a framework that minimized carbon emissions while meeting the energy demand for electric vehicles and buildings in a residential area. Haghifam et al. [59] integrated PHEVs and renewable energy sources with the gas and electricity infrastructure, using the energy hub approach. Operational costs decreased since less electricity was purchased from the grid.

\subsubsection{Hydrogen Economy}

With the aim of reducing greenhouse gas emissions, and utilizing distributed energy generation technologies, including hydrogen storage and fuel cell vehicles (FCVs), significant research has been carried out for developing a hydrogen economy for urban settlements [201-205]. Some notable studies, based on the energy hub concept, are shown below in Table 9. These studies consider hydrogen as an energy vector, which is an integral part of society. Therefore, they align with the goal of promoting a hydrogen economy [206].

Table 9. List of some research studies with hydrogen economy considerations within the energy hubs.

\begin{tabular}{|c|c|c|c|c|c|c|c|c|c|c|}
\hline \multirow{2}{*}{ Reference } & \multirow{2}{*}{ Paper } & \multicolumn{3}{|c|}{ Technology } & \multicolumn{5}{|c|}{ Energy Vectors } & \multirow{2}{*}{ Storage } \\
\hline & & CHP & Solar & Wind & Elec & NG & Heat & Bio & $\mathrm{H}_{2}$ & \\
\hline [16] & Hajimiragha et al. (2007) & $\checkmark$ & & & $\checkmark$ & $\checkmark$ & $\checkmark$ & & $\checkmark$ & $\mathrm{Y}$ \\
\hline [207] & Hajimiragha et al. (2008) & $\checkmark$ & & & $\checkmark$ & $\checkmark$ & $\checkmark$ & & $\checkmark$ & $\mathrm{Y}$ \\
\hline [183] & Del Real et al. (2010) & & $\boldsymbol{V}$ & & $\checkmark$ & & & & $\checkmark$ & $\mathrm{Y}$ \\
\hline [166] & Maniyali et al. (2013) & & $\checkmark$ & & $\checkmark$ & & & $\boldsymbol{V}$ & $\checkmark$ & $\mathrm{Y}$ \\
\hline [208] & Proietto et al. (2014) & & $\checkmark$ & $\checkmark$ & $\checkmark$ & & & & $\checkmark$ & $\mathrm{Y}$ \\
\hline [202] & Maroufmashat et al. - 1 (2015) & $\checkmark$ & $\checkmark$ & & $\checkmark$ & $\boldsymbol{V}$ & $\boldsymbol{V}$ & & $\checkmark$ & $\mathrm{Y}$ \\
\hline [204] & Maroufmashat et al. - 2 (2015) & $\checkmark$ & $\checkmark$ & & $\checkmark$ & $\checkmark$ & $\checkmark$ & & $\checkmark$ & Y \\
\hline [209] & Bucher et al. (2015) & & & & $\checkmark$ & & $\mathrm{H}_{2} \mathrm{O}, \mathrm{H}$ & & $\checkmark$ & Y \\
\hline [210] & Mukherjee et al. (2015) & & & & $\checkmark$ & $\checkmark$ & & & $\checkmark$ & Y \\
\hline [211] & Maroufmashat et al. (2016) & $\checkmark$ & $\checkmark$ & $\checkmark$ & $\checkmark$ & & & & $\checkmark$ & $\mathrm{Y}$ \\
\hline [212] & Ban et al. (2017) & $\checkmark$ & & $\checkmark$ & $\checkmark$ & $\boldsymbol{V}$ & $\checkmark$ & & $\checkmark$ & $\mathrm{Y}$ \\
\hline [213] & Mukherjee et al. - 1 (2017) & & & & $\checkmark$ & $\checkmark$ & & & $\checkmark$ & $\mathrm{Y}$ \\
\hline [214] & Mukherjee et al. - 2 (2017) & & & & $\checkmark$ & $\checkmark$ & & & $\checkmark$ & $\mathrm{Y}$ \\
\hline [215] & Mukherjee et al. - 3 (2017) & & $\checkmark$ & $\checkmark$ & $\checkmark$ & & & & $\checkmark$ & Y \\
\hline [216] & Baghaee et al.( 2017) & & $\checkmark$ & $\checkmark$ & $\checkmark$ & & & & $\checkmark$ & $\mathrm{Y}$ \\
\hline
\end{tabular}

Hydrogen has the potential to link multiple renewable and non-renewable energy resources in various applications. It can be easily generated through "clean" techniques, and vehicles can be promptly refueled with hydrogen [205]. With the rapid development of hydrogen vehicles, the development of a hydrogen economy has resulted in much research interest [203]. During the inception of the energy hub concept, Geidl and Andersson [6] discussed the possibility of including hydrogen within the hybrid system view. It had been perceived as a promising area of research that could facilitate other energy generation technologies, such as fuel cells and micro-turbines. Hajimiragha et al. [16] considered a comprehensive energy hub approach, within their research, focusing on the production, distribution, and utilization of hydrogen along with storage technologies. The study showed that greater flexibility was attained within the energy hub due to the inclusion of hydrogen; the latter 
allowed ease in the planning and operation of energy systems. This literature [207] applied the general optimal energy flow model of integrated energy systems to a three energy hub system comprised of electricity and natural gas networks, with electricity, heat, and hydrogen demands. The impact of the external hydrogen cost, as well as the size and efficiency of three major plants, i.e., electrolyzers, fuel cells, and CHP, on the optimal operation of the aforementioned integrated energy system was studied. For example, it explores the efficiency targets for electrolyzers and fuel cells for a given price of external hydrogen (produced by other processes) so that electrolysis-based hydrogen production and fuel cell-based power generation can be justified. Maroufmashat et al. [204] developed a generic mathematical model for the optimal energy management of a future hydrogen economy. In another study, Maroufmashat et al. [202] developed an MILP model of a network of smart energy systems to demonstrate the benefits of distributed hydrogen production within an urban dwelling. Based on an environmental and economic assessment, the study found that the distributed generation of hydrogen is beneficial over centralized hydrogen delivery. Moreover, it discussed how a network of energy hubs is economically and environmentally better than an independent hydrogen refueling station.

Maniyali et al. [166] developed an energy hub model to replace a coal-based power plant using nuclear power and hydrogen storage, illustrating the economic benefits of converting surplus off-peak power to hydrogen via electroyzers, in industrial and transport sectors. As discussed earlier, Del Real et al. [183] designed a residential solar power plant that comprised hydrogen and battery storage, considering seasonal variations of solar irradiation and temperature. The simulations indicated that hydrogen was excessively stored during the middle months of the year while being consumed in the earlier and later parts of the year.

Bucher et al. modeled the power-to-gas technology, through the energy hub approach, and conducted an evaluation study [209]. Power-to-gas includes the integration of the generation of hydrogen and biogas, and their distribution and storage through existing natural gas systems. It was found that the implementation of this technology was not currently viable (i.e., 2015). However, with further improvement in the efficiency of energy conversion systems and in the sale of hydrogen, the power-to-gas plants can become economically feasible. On the other hand, Mukherjee et al. [210] proposed an energy hub that considered natural gas when modeling power-to-gas technology. The model, which included hydrogen storage, proposed injecting hydrogen into the natural gas network. This action could potentially generate revenue from carbon credits brought about by reducing emissions. Therefore, in agreement with Bucher et al. [209], economic viability can increase with the sale of hydrogen. Another study, conducted by Mukherjee et al. [213], outlined the pricing mechanisms that can be optimized in order to achieve economic gains in the coming years. In a later study, Mukherjee et al. [214] modeled power-to-gas technology using a two-stage stochastic programming approach, that considered the uncertainty in hourly electricity price, the number of fuel cell vehicles serviced, and the amount of hydrogen refueled.

Ban et al. conducted a study regarding the integration of wind generation along with energy hubs consisting of electrolyzers and gas-to-power units [212]. The study illustrated the ability of the energy hubs to effectively manage a variable power profile using hydrogen storage technologies. Mukherjee et al. [215] designed a renewable, hydrogen-powered microgrid and studied its technical and economic viability using a case study in Canada. This microgrid was to serve as a backup power system to meet the energy demand for two days only using renewables and hydrogen. A comprehensive feasibility study showed that a higher pricing mechanism and government subsidies would be required to overcome the higher system cost [217].

\section{Modeling}

Energy hubs, in addition to optimal multi-energy carrier systems, are identified as interfaces between different energy generations and loads, as depicted in Figure $4[1,178]$. The unit is commonly comprised of three elements: direct connections, converters, and storage. The connections include the different energy carriers, i.e., electricity grid and natural gas that enter the system, as well as the 
outputs to the consumers. Energy hubs are composed of a set of conversion technologies and energy storage systems for the scheduled dispatch of various forms of energy.

The more notable advantages of this methodology are added reliability, load flexibility, and enhanced performance of the system [6]. Using the energy hub approach, a wide spectrum of energy-related problems can be addressed throughout the residential, commercial, and industrial areas [156].

Geidl et al. developed a model for multiple energy carrier systems and expressed the energy hub model in terms of energy conversion technologies; then, they incorporated energy storage systems [6]. They emphasized that their formulation of the energy hub leaves significant room for optimization since the efficiency of the technologies is nonlinear.

As illustrated in Figure 3, the energy from carrier 1 is split between energy conversion technologies A and B. In contrast, energy from carrier 2 is split into two further energy vectors after passing through the conversion technology C. D and $\mathrm{E}$ are other components for further conversions. For example, in the case where $C$ may be a co-generation system, $E$ may represent a chiller cascaded with $C$ to meet the demand of Load 2, which is the cooling load.

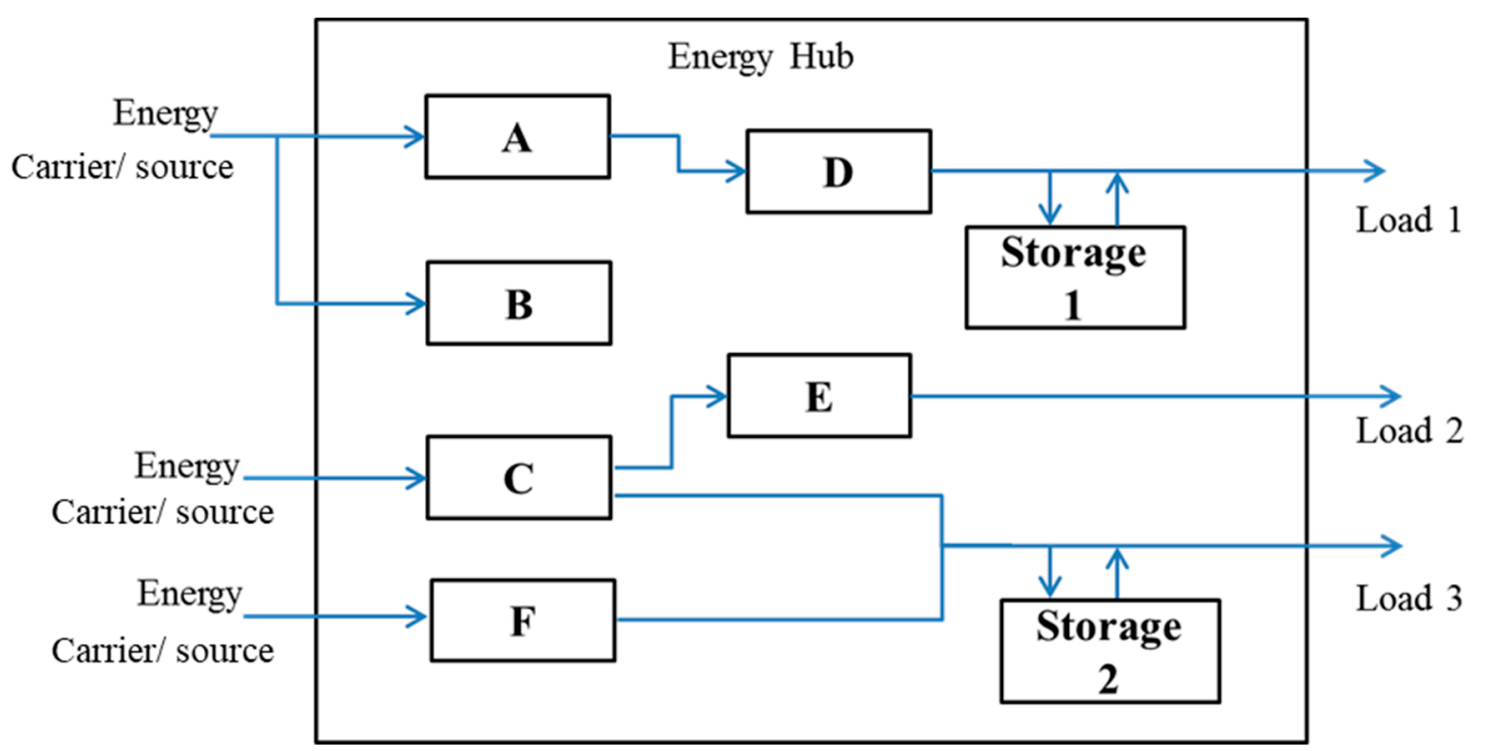

Figure 3. Illustration of a simple energy hub (adopted from [156]).

\subsection{Generic Framework}

One of the main objectives of future energy system projects [4] is to develop a generic modeling and analysis framework, in which the economical, ecological and technical effects related to systems can be studied. This generic structure would allow high flexibility in modeling without posing any constraint on the size of the system. Hence, to model an energy conversion technology, as described in the previous section, Geidl et al. [218] proposed using a coupling matrix $C$ that would transform the input energy to the required energy vectors. Maroufmashat et al. [144] modified this formulation, as shown in the following equation. Equation (1) shows a mathematical expression used to define the overall energy mapping process.

$$
\left[\begin{array}{c}
L_{1} \\
L_{2} \\
\cdot \\
L_{i} \\
\cdot \\
L_{I}
\end{array}\right]=\left[\begin{array}{cccc}
C_{11} & C_{12} & . . & C_{1 j} \\
C_{21} & C_{22} & . . & C_{2 j} \\
\cdot & \cdot & \cdot & \cdot \\
\cdot & \cdot & C_{i j} & \cdot \\
\cdot & \cdot & \cdot & \cdot \\
C_{I 1} & \ldots & C_{I J}
\end{array}\right]_{I \times J} \cdot I_{J \times J} \cdot \cdot \cdot\left[\begin{array}{c}
P_{1} \\
P_{2} \\
\cdot \\
P_{j} \\
\cdot \\
P_{J}
\end{array}\right]_{J \times 1}
$$


$\mathrm{L}$ and $\mathrm{P}$, in the above equation, denote the load demand and the input energy carrier $I, j$, respectively. $b$ is a vector that converts the units of energy from the input to power, consistent with that of the load. $I_{J \times J}$ is added to the equation to allow uniformity for matrix multiplication. The entities of the coupling matrix $C$ represent the efficiency with which energy is converted. If a particular entity within the coupling matrix is zero, it indicates that no conversion of energy is taking place. If a single conversion technology is utilized, the efficiency of that conversion process is considered the coupling factor. Additionally, if the load demand is the result of one or more energy conversion technologies, the product of the efficiencies is considered the coupling factor. On the other hand, the input energy carriers may possess certain operational limits, based on their capacities. Therefore, their power needs to be constrained by lower and upper boundaries (i.e., $\min / \mathrm{max}$ ), as expressed by Equation (2).

$$
P^{\min } \leq P(t) \leq P^{\max } \quad \forall t
$$

Many authors $[2,15,219]$ have introduced the "dispatching Factor" as a new variable to specify how much energy flows to Converter A and how much flows to Converter B. This was redundant as it could complicate the problem by introducing the further dimension of non-linearity.

Overall, this simple model can either be utilized under steady-state conditions or further developed to tackle dynamic systems with control strategies, while including energy storage and losses. Moreover, the unidirectional and bidirectional flow of power can be considered based on energy hub configuration [181]. For example, an electrical transformer would be able to realize reverse power flow whilst a turbine may not [6]. Based on this generic structure, the model opens a wide range of possibilities for optimization $[80,180,181]$. Stochastic models can be collated alongside the structure for the planning and operation of energy sources $[36,183,184]$. In addition, interactions between the energy carriers can be studied to assess the reliability and performance $[185,186]$.

\subsection{Energy Storage Modeling}

Energy storage is one of the key elements of the energy hub considered by Geidl et al $[1,4,6]$. More than half of the publications adhering to multi-energy systems have incorporated energy storage within their models, as evident from the classification. It is essential to account for time dependency when energy storage is considered, as energy accumulates over a certain period. Hence, the conversion technologies are perceived as discrete temporal systems [156].

$$
\dot{M}_{q}=\alpha_{q}^{c h} Q_{q}^{c h}-\frac{1}{\alpha_{q}^{d i s}} Q_{q}^{d i s}
$$

Equation (3) shows an energy balance of the storage technology, accounting for energy entering the storage system (i.e., charging) and leaving it (i.e., discharging). $Q_{q}^{c h}$ represents the power in-flow through the storage technology $q$ at an efficiency $\alpha_{q}^{c h}$, while $Q_{q}^{\text {dis }}$ represents the power flowing out of it at an efficiency of $\alpha_{q}^{\text {dis }}$.

As mentioned earlier, dynamic modeling is required when considering storage systems. Therefore, the storage function needs to be discretized into separate time periods, as has been done using the forward difference formula in Equation (4).

$$
\dot{M}_{q}=M_{q}(t)-M_{q}(t-1)+M_{q}^{s t d b y}
$$

$M_{q}(t)$ and $M_{q}(t-1)$ represent the energy stored in time periods $(t)$ and $(t-1)$, respectively. In order to account for losses, the $M_{q}^{\text {stdby }}$ term is added to the expression to express energy loss when the storage system is in its standby state. By compiling Equations (3) and (4), the overall equation for the $\mathrm{q}^{\text {th }}$ storage device at time period $(\mathrm{t})$ can be written as expressed in Equation (5).

$$
M_{q}(t)=M_{q}(t-1)+\alpha_{q}^{c h} Q_{q}^{c h}(t)-\frac{1}{\alpha_{q}^{d i s}} Q_{q}^{d i s}(t)-M_{q}^{s t d b y} \quad \forall \mathrm{q}, \forall \mathrm{t}
$$


In matrix representation, Equation (5) may be expressed as Equation (6).

$$
M(\mathfrak{t})=M(t-1)+A^{c h} Q^{c h}(t)-A^{d i s} Q^{d i s}(t)-M^{s t d b y} \quad \forall t
$$

As written, $A^{\text {ch }}$ and $A^{\text {dis }}$, in Equation (6), are diagonal matrices representing charging and discharging efficiencies, respectively, to allow matrix multiplication. In addition to the above model equations, technical constraints need to be structured to define the inability of the storage technology. For instance, simultaneous charging and discharging of a storage system is not possible. Hence, Equation (7) is comprised of two binary variables, $\delta_{q}^{\text {dis }}(t)$ and $\delta_{q}^{c h}(t)$, which are introduced for each storage technology at each time period $t$ to define the situation.

$$
\delta_{q}^{\text {dis }}(t)+\delta_{q}^{c h}(t) \leq 1
$$

Equation (8) shows the additional limitations on the capacity and exchange energy of each storage system.

$$
\begin{gathered}
M_{q}^{\min } \leq M_{q}(t) \leq M_{q}^{\max } \quad \forall q \cdot \forall t \\
\delta_{q}^{c h}(t) \cdot Q_{q}^{\text {ch,min }} \leq Q_{q}^{c h}(t) \leq \delta_{q}^{c h}(t) \cdot Q_{q}^{\text {ch.max }} \\
\delta_{q}^{\text {dis }}(t) \cdot Q_{q}^{\text {dis,min }} \leq Q_{q}^{\text {dis }}(t) \leq \delta_{q}^{\text {dis }}(t) \cdot Q_{q}^{\text {dis.max }}
\end{gathered}
$$

$M_{q}^{\min }$ and $M_{q}^{\max }$ represent the minimum and the maximum level of energy stored in the $\mathrm{q}^{\text {th }}$ storage system. Moreover, $Q_{q}^{\text {ch.min }}, Q_{q}^{\text {dis.min }}, Q_{q}^{\text {ch.max }}$ and $Q_{q}^{\text {dis.max }}$ represent the minimum and maximum energy that can flow through the $\mathrm{q}^{\text {th }}$ storage technology during the energy charging and discharging process.

\subsection{Network Modeling}

In many cases, a single energy hub model suffices for representing the entire energy system. Yet, for large-scale planning and operational problems, a network of energy hubs is considered $[156,178,189,200]$. These energy hubs are interconnected, facilitating energy transfer among them.

Figure 4 shows a network of energy hubs with a focus on energy hub s. Each energy hub within the network either receives energy from outside the network (i.e. grid, renewable energy sources, etc.) or from other energy hubs in the network. Likewise, each energy hub produces energy to meet the demand within the hub or to supply other interconnected energy hubs. As is evident in Figure 4, three energy carriers have a flow of power into energy hub $s$. The total energy from hub s supplied to other connected energy hubs is represented by $T_{s}$. This total is the summation of the individual energy output, $\operatorname{Tr}_{s k}$, to each connected energy hub, $k$, from energy hub $s$. This relationship can be expressed mathematically in the following way:

$$
T_{s}=\sum_{k \in S-\{s\}} T r_{s k}
$$




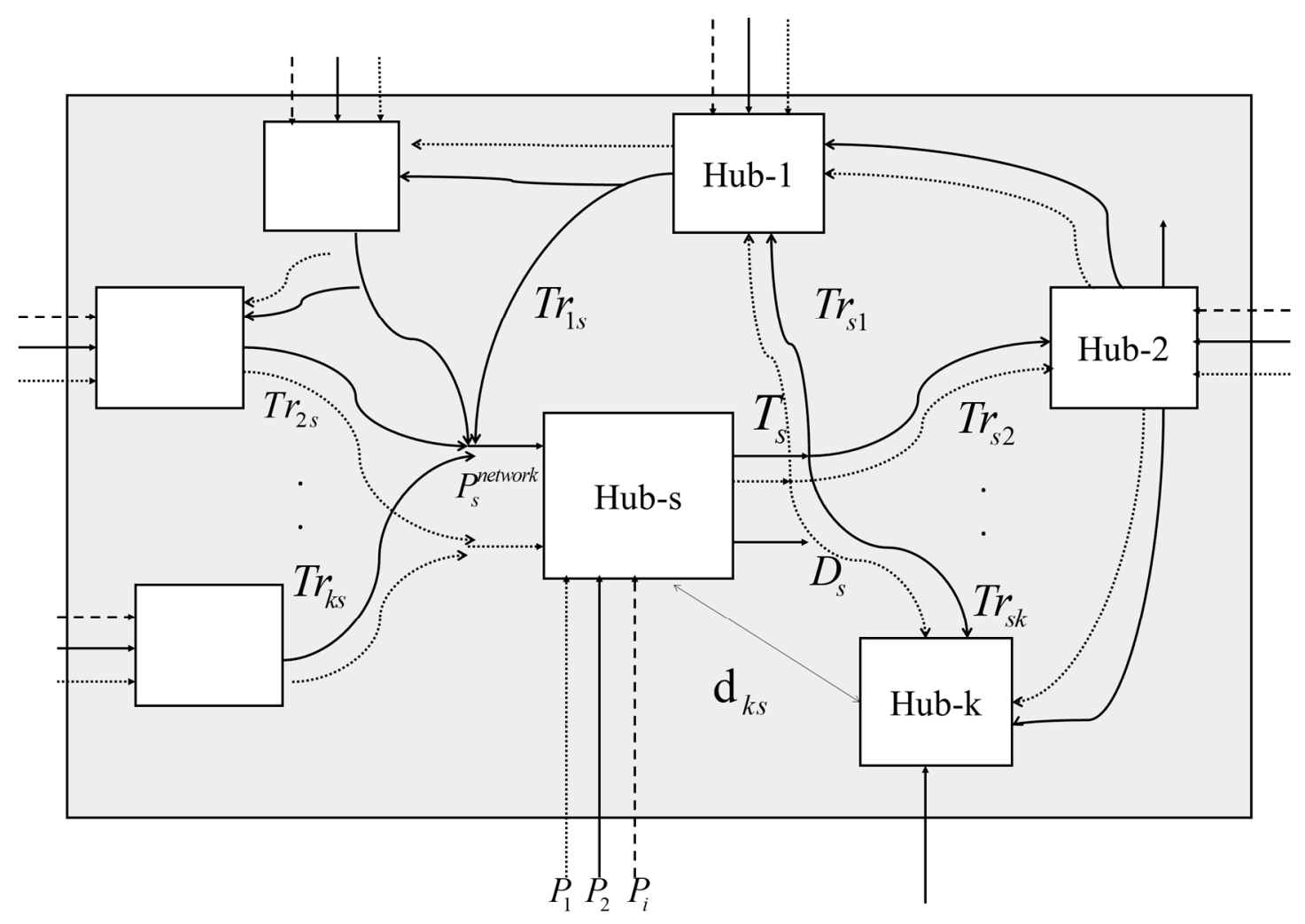

Figure 4. Illustration of the interconnected energy hubs [156].

Similar to the coupling factors in the coupling matrix, as well as energy storage efficiencies, a coefficient may be multiplied by $T r_{s k}$ to account for the losses due to the transmission of energy from energy hub $s$ to $k$. All the energy vectors that exist between the interconnected energy hubs can be written in matrix form, as shown below.

$$
\left[\begin{array}{c}
T_{1} \\
T_{2} \\
\cdot \\
\cdot \\
\cdot \\
T_{S} \\
\cdot \\
\cdot \\
T s
\end{array}\right]_{S \times 1}=\left[\begin{array}{ccccc}
0 & \operatorname{Tr}_{12} & \operatorname{Tr}_{13} & \cdots & \operatorname{Tr}_{1 k} \\
\operatorname{Tr}_{21} & 0 & \operatorname{Tr}_{23} & \cdots & \operatorname{Tr}_{2 k} \\
\cdot & \cdot & \cdots & & \\
\cdot & \cdot & \cdots & & \\
\cdot & \cdot & \cdots & & \\
\operatorname{Tr}_{s 1} & \operatorname{Tr}_{s 2} & \cdots & & \operatorname{Tr}_{s k} \\
\cdot & & & & \\
\cdot & & & & \\
T r & & \cdots & & 0
\end{array}\right]_{S \times S}\left[\begin{array}{c}
1 \\
1 \\
\cdot \\
\cdot \\
\cdot \\
1 \\
\cdot \\
1
\end{array}\right]_{S \times 1}
$$

The first column vector contains the sum of all energy vectors leaving a particular energy hub (i.e., $T_{s}$ ). The $\operatorname{Tr}$ matrix contains each vector that leaves a particular energy hub $s$ and enters energy hub $k$. The column vector on the right-hand side of the expression is a vector with each element equal to 1 to allow matrix multiplication.

\section{Optimization Problem for the Energy Hub Concept}

Mathematical programming, better known as optimization, is the scientific method used to analyse complex models. The purpose of optimization is to help alleviate the toll of decision-making with respect to quantifiable systems with a large number of possible solutions. Cost reduction is a major concern for energy hub installations. Depending on the energy hub application, a wide variety of converters, e.g., energy generation and/or storage devices, may exist with different start-up/shut-down costs, as well as fuel consumption rates or efficiencies. Moreover, there are plenty of operational 
constraints/limitations specific to each asset. In view of all these considerations, making decisions about controlling the energy hub, e.g., dispatching different converters to achieve minimum operational and environmental costs, is a challenging task that cannot usually be done through a simple rule-based approach. Instead, this challenge should be resolved through an optimization process, commonly referred to as energy hub optimal dispatch or the generation scheduling problem, which is basically a multi-interval optimization problem since the decisions are made for the present and future time, i.e., the prediction horizon. This optimization problem should include a variety of operational considerations, such as the lower and upper bounds of powers/charge states and the number of start-ups/shut-downs, ramp rates, loading factors, and minimum up-time/down-time [123]. To model these operational considerations, discrete (integer/binary) variables and complex constraints need to be defined; these definitions result in mixed integer linear/non-linear programming (MILP/MINLP) formulations. Since the status of assets in the hub, e.g., availability or offline/online states, may change over time, and loads, renewable power sources, and energy prices have a time-varying nature, decisions must be updated by rerunning the optimization calculations every few minutes/hours, i.e., the dispatch time. This method is commonly referred to as rolling time horizon (RTH) or model predictive control (MPC) [220-222].

In general, in the context of energy hub cost minimization or the optimal dispatch problem, two approaches are distinguished, namely, open-loop and closed-loop optimization. In open-loop optimization [223], decision variables $X_{0}, X_{1}, X_{2}, \ldots, X_{k}$ are made at once at time 0 , without waiting to see the subsequent demand, renewable power, and energy price levels. This solution can be obtained by the previously-mentioned MILP/MINLP formulations. In closed-loop optimization [224], the decision variable $X_{k}$ is postponed until the last possible moment (time k), when the current system state, e.g., demands, renewable powers, energy prices, and storage charge levels, will be known. In fact, the information that becomes available between time 0 and $\mathrm{k}$ is used to enhance the quality of the decisions. In this type of optimization approach, finding the optimal numerical values of the decisions is not the matter of concern; instead, the objective is to find an optimal rule or function for selecting a decision $X_{k}$ at each period of $k$ for each possible value of the system state that can occur. MPC/RTH is an approximate solution for closed-loop optimization; however, it is computationally expensive for real-world applications as the whole optimization problem is resolved at every single time step after updating the expectations. For a limited dispatch time, e.g., few minutes and typical energy hub configurations with limited numbers of generation and storage assets, one needs to deal with an extremely large problem with complex constraints. It is difficult to implement and be solved by an embedded energy management or supervisory control system with a limited memory and processing capability. Most of the existing contributions within the area of energy hub optimal dispatch fall into the category of open-loop and MPC approaches [115,225-227]. To illustrate, reference [120] is a new attempt to introduce a closed-loop optimization approach to the field of energy hubs.

Terms of nonlinearity in the energy hub modeling depend on the objective function and the coupling matrix variables. One can use the energy hub model for the optimal design and operation of complex integrated energy systems. In this part, some techniques are presented to linearize energy hub modeling for the optimal design and operation of a hybrid energy system.

The variable and linearity classification is further broken-down into three sub-classifications based on whether non-linear and linear terms exist in the constraints and objective function, namely, linear programming (LP), non-linear programming (NLP), and mixed integer linear programming (MILP).

LP provides a solution that must satisfy all linear constraints and determines the minimum or maximum value of the defined linear objective function. LP methods are the fastest of the three types of programs. They are useful for the operational optimization of an energy hub when there is no energy storage in the system $[11,204]$.

Nonlinear programming (NLP) consists of linear and nonlinear objective functions and constraints; either the constraints or the objective function must incorporate one nonlinear term. In problem solving, both the theoretical and practical features of NLP problems are considered, rendering them more difficult to solve than LPs. Mathematical formulation, algorithm development, and the analysis 
of a specific problem are all practical issues. One method of solving an NLP problem is by removing the variable with the nonlinear term from the formula and solving the given problem explicitly. NLP is the slowest of the three mathematical methods. Here, we present some methods to convert nonlinearity in the objective function or in the coupling matrix of an energy hub in linear programming to make it easier to solve and find the global optimized solution [228].

Models that consist of both continuous and integer variables are known as mixed-integer programming (MIP). Generally, MIPs are expressed as follows:

$$
\begin{gathered}
\min f(x \cdot y) \\
\text { subject to } g(x \cdot y) \leq b \\
x_{\min } \leq x \leq x_{\max } \\
y \in\{0.1\}^{q}
\end{gathered}
$$

The model uses finite variables with integer values, such as the existence or nonexistence of power plant units as a binary variable termed one or zero, respectively. Another example is a tray of distillation columns, with terms one, two, three, etc. If only the integer variables are used, the problem is classified as an integer programming (IP) model. Finally, if only variables with the values of $1-0$ are used, the problem is considered a binary integer programming (BIM) model. Moreover, the MILP model only consists of linear equalities and inequalities, while the MINLP model includes linear and nonlinear ones. The most advantageous attribute of MILP is its ability to formulate logical constraints. The MILP's integer variable property allows for the modeling of non-convexities. On the other hand, the MILP's greatest disadvantage is its lack of a standard formulation or analytical solution $[229,230]$. In addition, MILP problems are much more difficult to solve than LP problems.

\subsection{Formulation of Strategies for MILP}

The main objective of using mixed-integer linear programming (MILP) according to [231] is to provide a statement of the actions performed, allowing the system to move from a primary status toward the defined objective.

The program's developer is responsible for meeting the stated objective, as well as incorporating detailed components of the system. The modeler's most important function is to ensure that there is a compromise between tractable formulations and representational fidelity. Introducing additional binary variables to an MILP problem, unlike LP, is advantageous as it reduces the number of branches that must be searched. Contrary to LP-based problems, the addition of constraints in MILP is used to reformulate so that the convex hull of feasible continuous variables approaches the convex hull of feasible integer variables.

\subsection{Solution Strategies}

MILP-based problems are generally difficult to solve through the simplex algorithm [231]. In fact, there is no defined systematic method to solve such problems; rather, the existing solution algorithms may take an exponential amount of time or, even worse, only provide an approximation. Regarding reference [232], the following is a list of the methods developed to solve integer programming problems. The first group includes exact algorithms (rounding method, cutting-plane method, dynamic programming), which guarantee an optimal solution, but require an exponential number of iterations. The second group includes approximate algorithms, which provide less accurate solutions by bounding the sub-optimal solution using a heuristic algorithm. Lastly, the most reliable branch-and-bound method considers each problem as a binary tree whose efficiency is dependent on the quality of the bounds at each node of the solution tree. 


\subsection{Strategies to Linearize the Energy Hub Model}

Adopting different objectives in the process of optimization leads to a nonlinear model for the energy hub. Some useful steps can convert the nonlinear term to a mixed integer programming model. To illustrate this, when dealing with nonlinearity in the design and planning of energy systems based on energy hubs, determining the number of fixed-size technologies can be a challenging problem. In order to change the integer variables to binary ones, the following equation can be implemented:

$$
N=y_{0} \cdot 2^{0}+y_{1} \cdot 2^{1}+y_{2} \cdot 2^{2}+y_{3} \cdot 2^{3}+\cdots+y_{n} \cdot 2^{n} \quad N_{\min } \leq N \leq N_{\max }
$$

where $\mathrm{N}$ is an integer variable and $y_{i}$ represents binary ones.

By this conversion, it is easier to convert nonlinear terms to mixed-integer ones; specifically, when the multiplication of integer and continuous variables is involved. This paper will explain later how the multiplication of binary and continuous variables can be linearized.

The efficiencies of energy conversion technologies vary as the load changes. The relation between the output $(\mathrm{L}(\mathrm{t}))$ and input power $(\mathrm{p}(\mathrm{t}))$ of energy conversion technologies depends on the efficiency, which is a function of several variables, such as the operational condition or even output power. The efficiency of an energy conversion technology can be presented as a function of other variables, resulting in nonlinearity in the modeling of energy hubs. Therefore, the optimization of such a system creates more difficulties.

Piecewise linear formulation is employed for a variety of applications to estimate nonlinear functions, either in objective functions or problem constraints, through the addition of more continuous and discrete variables. This kind of formulation can be applied in different domains, such as transportation and production planning. The application of this technique in engineering design, as well as process systems, is also presented in [233-235]. In addition, it can be used for the planning of natural gas networks [236]. Different approaches have been implemented for the piece-wise linearization of nonlinear functions [237-240]. The incremental cost and convex combination are two types of mixed integer formulation [241].

Nonlinear functions, along with various integer variables, can be incorporated into an MINLP-based model, which is one of the hardest types of optimization problems to solve. It is possible to perform a piecewise linearization of the nonlinear functions and convert them to an MILP. The solution procedure for integer programming is fully developed; however, the number of integer variables is noticeably increased by employing an MILP-based model, leading to a lower accuracy of the optimization solution. The prior literature suggests that the advantages of an MIP-based model far outweigh the objections [242]. The stepwise formulation is typically employed to model the efficiency of resources over time. It is a special case of the piecewise linear function where all the slopes are equal to zero.

Through energy hub modeling, as can be seen in Equation (1), there is a nonlinearity due to the multiplication of two continuous variables, including the coupling matrix $(C(t))$ and input power flow $(P(t))$. The coupling matrix can become a step-wise linearization, as shown in Equation (13). Therefore, the nonlinear product becomes the product of one binary variable and one continuous variable, which can be transformed to the MIP-based problem:

$$
L_{i}(t)=\sum_{j} C_{i, j}(t) \cdot P_{j}(t) \cdot b_{j}=\sum_{j}\left(\sum_{k} n_{i, j, k}(t) \cdot y_{i, j, k}(t)\right) \cdot P_{j}(t) \cdot b_{j} .
$$

where, $n_{i, j, k}$ is the step-wise efficiency and $y_{i, j, k}$. is the binary variable regarding the selection of the step-wise efficiency and $k$ represents the number of steps.

To implement this method, the curve of part load efficiency is estimated as a piecewise constant function, the step length is not fixed, and the optimum step length of each piece can be determined by minimizing its error. Different methods were applied to this problem in the literature, including analytical methods and dynamic programming $[243,244]$. 
To select only one piece in each step, Equation (14) is introduced. The upper and lower bound of each step is constrained by the following equation:

$$
\sum_{k} y_{i, j, k}=1 .
$$

By piecewise constant linearization of efficiency, nonlinearity remains in the equations due to the product of step-wise binary variables (y) and the input energy flow to each energy hub $((\mathrm{p}(\mathrm{t}))$. This nonlinearity can be converted into bilinear products by employing the procedure stated in [245], [246]. In order to solve this issue, a new variable $(\mathscr{P})$, which is the multiplication of the binary variable (y) and continuous variable (P), is added to the model along with the following constraints (Equation (15) and Equation (16)):

$$
\begin{gathered}
n_{i, j, k} \cdot y_{i, j, k} \cdot P_{j, k}=P_{i, j, k}^{\prime} \quad 0 \leq P_{i, j, k}^{\prime} \leq n_{i, j, k} \cdot P_{j} . \\
n_{i, j, k} \cdot P_{j}-n_{i, j, k}^{\max } \cdot P_{j}^{\max }\left(1-y_{i, j, k}\right) \leq P_{i, j, k}^{\prime} \leq n_{i, j, k}^{\max } \cdot P_{j}^{\max } \cdot y_{i, j, k}
\end{gathered}
$$

where, $\eta^{\max }, P^{\max }$ are the upper limit of efficiency and input power, respectively.

\section{Summary and Concluding Points}

Several studies have been carried out in the area of synergistic optimal energy transformation, storage, and carrier problems. The energy hub approach has played a vital role in addressing such problems. Many researchers have utilized this methodology and extended this concept in modeling, optimization, and application. This paper has mainly presented a comprehensive review of energy hub modeling and optimization. It constitutes an introduction to this novel concept with various definitions of this proposed idea. Furthermore, it outlines the importance of smart energy systems and demonstrates the advancement of the energy hub approach since its inception. In addition, the use of different energy generation, conversion, and storage technologies in each study is outlined. This paper considers previous review studies that have focused on energy hubs or multi energy systems or other aspects pertaining to them. These review studies have focused on effectively defining the energy hub concept, but gaps remain in the areas of modeling, optimization, and energy hub application.

Among the various themes identified within this paper, planning and operation is a major one in which significant research work has been carried out regarding the scheduling and control methodologies for energy hubs. Due to the intermittent nature of renewables, controllers are needed to ensure that an optimal and reliable power flow will be satisfied in the energy hub. In addition, assessment studies regarding the scheduling scheme of energy hubs and control technologies were discussed. In addition to reliability studies, various research has focused on the economic and environmental considerations of energy hubs; this research includes studies with single objective functions to optimize the cost or greenhouse gas emissions and multi-objective functions to incorporate both. A number of studies that have presented case studies to illustrate the economic and environmental gain due to the energy hub approach have been mentioned. In terms of application, the studies in which energy hubs are commonly considered have been outlined. It is noteworthy that we have categorized the application of this approach based on the design and management of distributed energy resources and plug-in hybrid vehicles (PHEV), as well as on the development of a hydrogen economy. In each of these areas, the contributions made by researchers have been listed, and the important findings have been emphasized. For distributed energy systems, the results demonstrate that the energy hub-modeling tool is capable of simulating systems at various levels and sizes. Studies on battery electric vehicles (BEV) and PHEVs state that this approach opens a wide space for optimization. In the development of a hydrogen economy, the ability of smart energy systems to consider the hydrogen vector results in a significant decrease in costs and carbon emissions. Since hydrogen is one of the promising energy vectors of future energy systems, the energy hub approach can help integrate the whole system while considering the hydrogen economy. 
In the modeling section, a generic framework for smart energy system modeling has been presented. Provisions for modeling storage technologies and modeling a network of energy hubs have also been illustrated in a step-by-step manner. The optimization strategies for facing energy hub modeling issues have been described. Different strategies to linearize the energy hub model and convert it to the MILP-based model have been introduced.

Future work regarding energy hubs will be at the cutting edge of the use of artificial intelligence for the modeling and optimization of energy hubs; smart energy systems including smart homes and smart cities; and the hydrogen economy for sustainable transportation systems, as well as for industrial facilities. The direction of future work regarding energy hubs lies at the intersection of artificial intelligence and the hydrogen economy. Artificial intelligence can be used to model and optimize energy hubs or smart energy systems (e.g., smart homes and smart cities), whereas the hydrogen economy targets sustainable transportation systems and industrial facilities.

Conflicts of Interest: The authors declare no conflict of interest.

\section{Abbreviations}

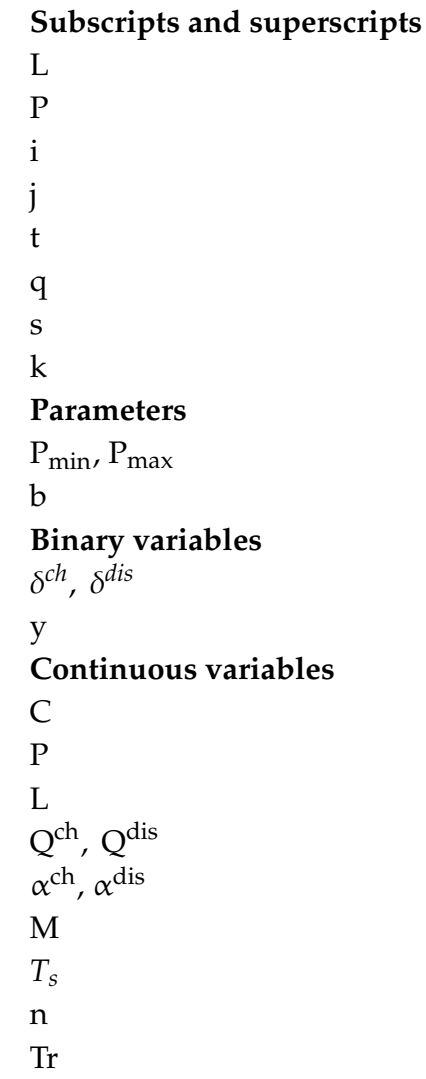

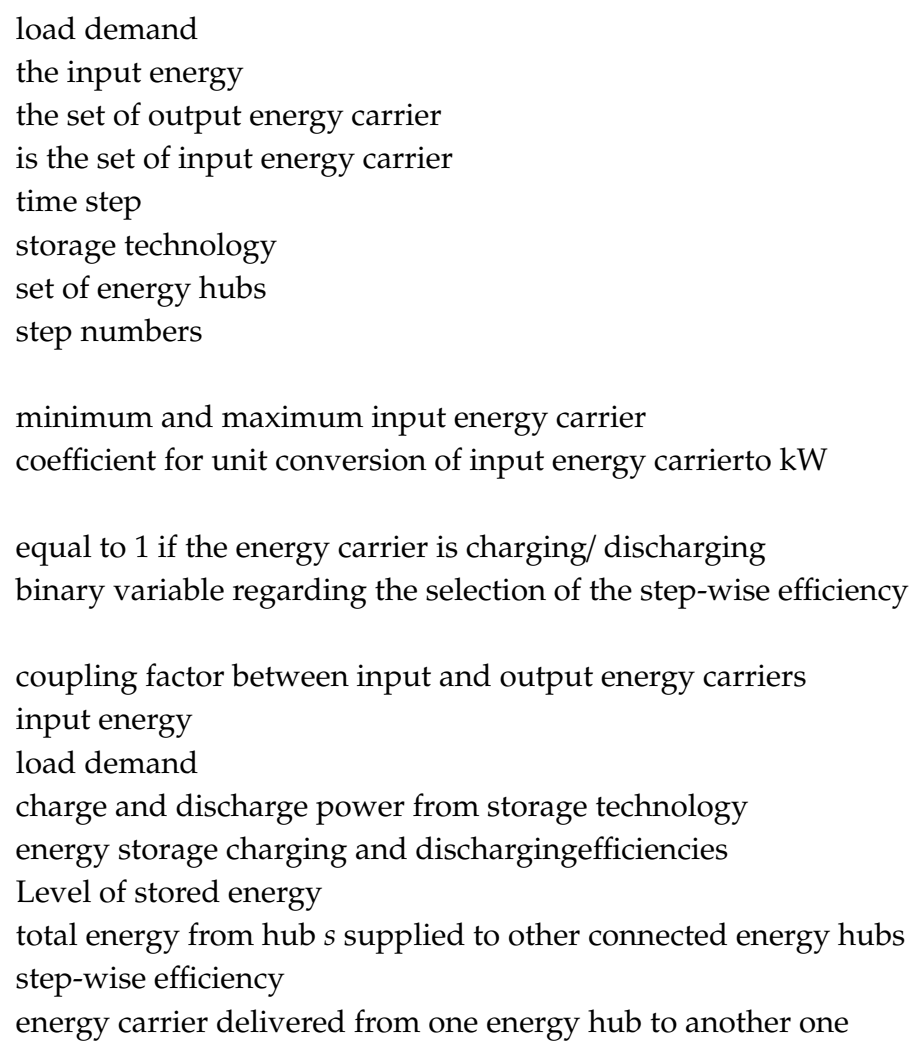

\section{References}

1. Geidl, M.; Koeppel, G.; Favre-perrod, P.; Klöckl, B.; Andersson, G.; Fröhlich, K. The Energy Hub—A Powerful Concept for Future Energy Systems. In Proceedings of the Third Annual Carnegie Mellon Conference on the Electricity Industry, Pittsburgh, PA, USA, 13-14 March 2007; pp. 1-10.

2. Geidl, M.; Favre-Perrod, P.; Klöckl, B.; Koeppel, G. A greenfield approach for future power systems. In Proceedings of the 41st CIGRE Session 2006, Paris, France, 27 August-1 September 2006; p. 10.

3. Favre-Perrod, P. A vision of future energy networks. In Proceedings of the 2005 IEEE Power Engineering Society Inaugural Conference and Exposition in Africa, Durban, South Africa, 11-15 July 2005.

4. Geidl, M.; Koeppel, G.; Favre-Perrod, P.; Klockl, B.; Andersson, G.; Frohlich, K. Energy hubs for the future. IEEE Power Energy Mag. 2007, 5, 24-30. [CrossRef] 
5. Lund, H.; Andersen, A.; Østergaard, P.; Vad Mathiesen, B.; Connolly, D. From electricity smart grids to smart energy systems-a market operation based approach and understanding. Energy 2013, 42, 96-102. [CrossRef]

6. Geidl, M.; Andersson, G. A modeling and optimization approach for multiple energy carrier power flow. In Proceedings of the 2005 IEEE Russia PowerTech, St. Petersburg, Russia, 27-30 June 2005; pp. 1-7.

7. Walker, S.B.; Mukherjee, U.; Fowler, M.; Elkamel, A. Benchmarking and selection of Power-to-Gas utilizing electrolytic hydrogen as an energy storage alternative. Int. J. Hydrog. Energy 2016, 41, 7717-7731. [CrossRef]

8. Grosspietsch, D. Distributed multi-energy-hubs: A review and technoeconomic model to assess viability and potential pathways. In Proceedings of the Energy Science Technology Conference 2015, Karlsruhe, Germany, 20-22 May 2015; p. 21.

9. Lund, H.; Werner, S.; Wiltshire, R.; Svendsen, S.; Thorsen, J.E.; Hvelplund, F.; Mathiesen, B.V. 4th Generation District Heating (4GDH): Integrating smart thermal grids into future sustainable energy systems. Energy 2014, 68, 111. [CrossRef]

10. Lund, H. Renewable heating strategies and their consequences for storage and grid infrastructures comparing a smart grid to a smart energy systems approach. Energy 2018, 151, 94102. [CrossRef]

11. Koeppel, G.; Andersson, G. The Influence of Combined Power, Gas, and Thermal Networks on the Reliability of Supply. In Proceedings of the Sixth World Energy System Conference, Torino, Italy, 10-12 July 2006; pp. 646-651.

12. Koeppel, G.; Andersson, G. Reliability modeling of multi-carrier energy systems. Energy 2009, 34, $235-244$. [CrossRef]

13. Galus, M.D.; la Fauci, R.; Andersson, G. Investigating PHEV wind balancing capabilities using heuristics and model predictive control. In Proceedings of the IEEE PES General Meeting, PES, Providence, RI, USA, 25-29 July 2010.

14. Ulbig, A.; Galus, M.D.; Chatzivasileiadis, S. General Frequency Control with Aggregated Control Reserve Capacity from Time-Varying Sources: The Case of PHEVs. In Proceedings of the 2010 IREP Symposium-Bulk Power System Dynamics and Control-VIII (IREP), Rio de Janeiro, Brazil, 1-6 August 2010; pp. 1-15.

15. Hemmes, K. Integration of fuel cells in multisource multiproduct energy systems. In Proceedings of the ASME 2006 4th International Conference on Fuel Cell Science, Engineering and Technology, Irvine, CA, USA, 19-21 June 2006; pp. 4-8.

16. Hajimiragha, H.; Canizares, C.; Fowler, M.; Geidl, M.; Andersson, G. Optimal Energy Flow of Integrated Energy Systems with Hydrogen Economy Considerations. In Proceedings of the 2007 iREP Symposium-Bulk Power System Dynamics and Control-VII. Revitalizing Operational Reliability, Charleston, SC, USA, 19-24 August 2007; pp. 1-11.

17. Manusov, V.; Kirgizov, A.; Ahyoev, J. Construction and optimization of a power complex with a distributed generation on the basis of renewables and methods of artificial intelligence ( on the example of the Republic of Tajikistan ). E3S Web Conf. 2016, 3006, 1-8. [CrossRef]

18. Rubio-Barros, R.; Ojeda-Esteybar, D.; Vargas, A. Energy Carrier Networks: Interactions and Integrated Operational Planning BT. In Handbook of Networks in Power Systems II; Sorokin, A., Rebennack, S., Pardalos, P.M., Iliadis, N.A., Pereira, M.V.F., Eds.; Springer: Berlin/Heidelberg, Germany, 2012; pp. 117-167.

19. Galus, M.D.; Waraich, R.A.; Noembrini, F.; Steurs, K.; Georges, G.; Boulouchos, K.; Axhausen, K.W.; Andersson, G. Integrating power systems, transport systems and vehicle technology for electric mobility impact assessment and efficient control. IEEE Trans. Smart Grid 2012, 3, 934-949. [CrossRef]

20. Pazouki, S.; Haghifam, M.R.; Moser, A. Uncertainty modeling in optimal operation of energy hub in presence of wind, storage and demand response. Electr. Power Energy Syst. 2014, 61, 335345. [CrossRef]

21. Pazouki, S.; Haghifam, M.R.; Olamaei, J. Economical scheduling of multi carrier energy systems integrating Renewable, Energy Storage and Demand Response under Energy Hub approach. In Proceedings of the Smart Grid Conference 2013, SGC 2013, Tehran, Iran, 17-18 December 2013; pp. 80-84.

22. Fabrizio, E.; Filippi, M.; Virgone, J. Trade-off between environmental and economic objectives in the optimization of multi-energy systems. Build. Simul. 2009, 2, 29-40. [CrossRef]

23. Dai, Y.; Wang, J. A modeling and optimization approach for multi-carrier energy system considering the interaction between energy, product and emission. Biotechnol. Indian J. 2009, 8, 848-854.

24. del Real, A.J.; Arce, A.; Bordons, C. Combined environmental and economic dispatch of smart grids using distributed model predictive control. Int. J. Electr. Power Energy Syst. 2014, 54, 65-76. [CrossRef] 
25. Wang, Y.; Zeng, P.; Zhang, H.; Liu, Y.; Wang, T.; Kuang, F. Information-centric Industrial Internet of Things: Energy model. In Proceedings of the 2012 IEEE 2nd International Conference on Cloud Computing and Intelligence Systems (CCIS 2012), Hangzhou, China, 30 October-1 November 2012; pp. 1-6.

26. Restrepo, A.R.; Manotas, D.F.; Lozano, C.A. Self-generation of Electricity, Assessment and Optimization under the New Support Schemes in Colombia. IEEE Lat. Am. Trans. 2016, 14, 1308-1314. [CrossRef]

27. Rayati, M.; Sheikhi, A.; Ranjbar, A.M. Optimising operational cost of a smart energy hub, the reinforcement learning approach. Int. J. Parallel Emergent Distrib. Syst. 2015, 30, 325-341. [CrossRef]

28. Pazouki, S.; Haghifam, M.-R.; Pazouki, S. Transition from fossil fuels power plants toward Virtual Power Plants of distribution networks. In Proceedings of the 2016 21st Conference on Electrical Power Distribution Networks Conference (EPDC), Karaj, Iran, 26-27 April 2016; pp. 82-86.

29. Buehler, R. Integration of Renewable Energy Sources Using Microgrids, Virtual Power Plants and the Energy Hub Approach. Bachelor's Thesis, Swiss Federal Institute of Technology, Zurich, Switzerland, 2010.

30. Bozchalui, M.C.; Hashmi, S.A.; Hassen, H.; Cañizares, C.A.; Bhattacharya, K. Optimal operation of residential energy hubs in smart grids. IEEE Trans. Smart Grid 2012, 3, 1755-1766. [CrossRef]

31. Paudyal, S. Optimal Energy Management of Distribution Systems and Industrial Energy Hubs in Smart Grids. Ph.D. Thesis, University of Waterloo, Waterloo, ON, Canada, 2012.

32. Krause, T.; Andersson, G.; Frohlich, K.; Vaccaro, A. Multiple-energy carriers: Modeling of production, delivery, and consumption. Proc. IEEE 2011, 99, 15-27. [CrossRef]

33. Mohammadi, M.; Noorollahi, Y.; Mohammadi-ivatloo, B.; Yousefi, H. Energy hub: From a model to a concept-A review. Renew. Sustain. Energy Rev. 2017, 80, 1512-1527. [CrossRef]

34. Phdungsilp, A.; Martinac, I. Distributed energy resources systems towards carbon- neutral urban development: A review and application. Int. J. Energy Environ. 2016, 7, 77-88.

35. Mancarella, P. MES (multi-energy systems): An overview of concepts and evaluation models. Energy 2014, 65, 1-17. [CrossRef]

36. Chicco, G.; Mancarella, P. Distributed multi-generation: A comprehensive view. Renew. Sustain. Energy Rev. 2009, 13, 535-551. [CrossRef]

37. Howell, S.; Rezgui, Y.; Hippolyte, J.L.; Jayan, B.; Li, H. Towards the next generation of smart grids: Semantic and holonic multi-agent management of distributed energy resources. Renew. Sustain. Energy Rev. 2017, 77, 193-214. [CrossRef]

38. Houwing, M.; Heijnen, P.; Bouwmans, I. Socio-technical complexity in energy infrastructures conceptual framework to study the impact of domestic level energy generation, storage and exchange. In Proceedings of the IEEE International Conference on Systems, Man and Cybernetics, Taipei, Taiwan, 8-11 October 2006; pp. 906-911.

39. Alizadeh, M.I.; Moghaddam, M.P.; Amjady, N.; Siano, P.; Sheikh-El-Eslami, M.K. Flexibility in future power systems with high renewable penetration: A review. Renew. Sustain. Energy Rev. 2016, 57, 1186-1193. [CrossRef]

40. Favre-Perrod, P.; Critchley, R.; Catz, E.; Bazargan, M. New participants in SmartGrids and associated challenges in the transition towards the grid of the future. In Proceedings of the 2009 IEEE Bucharest PowerTech: Innovative Ideas Toward the Electrical Grid of the Future, Bucharest, Romania, 28 June-2 July 2009.

41. Liserre, M.; Sauter, T.; Hung, J.Y. Future energy systems: Inegrating renewable energy into the smart power grid through industrial electronics. IEEE Ind. Electron. Mag. 2010, 4, 18-37. [CrossRef]

42. Liu, M.; Shi, Y.; Fang, F. Combined cooling, heating and power systems: A survey. Renew. Sustain. Energy Rev. 2016, 35, 122. [CrossRef]

43. Rubio, R.; Ojeda-Esteybar, D.; Ano, O.; Vargas, A. Integrated natural gas and electricity market: A survey of the state of the art in operation planning and market issues. In Proceedings of the 2008 IEEE/PES Transmission and Distribution Conference and Exposition: Latin America, Bogota, Colombia, 13-15 August 2008; pp. 1-8.

44. Rubio-Barros, R.; Ojeda-Esteybar, D.; Ano, O.; Vargas, A. Combined operational planning of natural gas and electric power systems: State of the art. In Natural Gas; Potocnik, P., Ed.; Sciyo: Rijeka, Rijeka, 2010; p. 616.

45. Smart energy systems and 4th generation district heating. Energy 2016, 110, 1-4. [CrossRef]

46. Mancarella, P.; Andersson, G.; Peças-Lopes, J.A.; Bell, K.R.W. Modelling of integrated multi-energy systems: Drivers, requirements, and opportunities. In Proceedings of the 19th Power Systems Computation Conference, PSCC 2016, Genoa, Italy, 20-24 June 2016. 
47. Allegrini, J.; Orehounig, K.; Mavromatidis, G.; Ruesch, F.; Dorer, V.; Evins, R. A review of modelling approaches and tools for the simulation of district-scale energy systems. Renew. Sustain. Energy Rev. 2015, 52, 1391-1404. [CrossRef]

48. Chiang, N.-Y.; Zavala, V.M. Emerging Optimal Control Models and Solvers for Interconnected Natural Gas and Electricity Networks. In Alternative Energy Sources and Technologies; Martín, M., Ed.; Springer International Publishing: Cham, Switzerland, 2016; pp. 89-115.

49. Rong, A.; Su, Y. Polygeneration Systems in Buildings: A Survey on Optimization Approaches. Energy Build. 2017, 151, 439-454. [CrossRef]

50. Van Beuzekom, I.; Gibescu, M.; Slootweg, J.G. A review of multi-energy system planning and optimization tools for sustainable urban development. In Proceedings of the 2015 IEEE Eindhoven PowerTech, Eindhoven, The Netherlands, 29 June-2 July 2015; pp. 1-7.

51. Klöckl, B.; Fröhlich, K.; Kaltenegger, K. New Energy Technologies, New Requirements on Electricity and an Unresolved Transition Problem Towards Sustainability: Is There Need for Basic Academic Research? In Proceedings of the Cigré 5th Southern Africa Regional Conference, Cape Town, South Africa, 25-27 October 2005; pp. 1-7.

52. Shabanpour-Haghighi, A.; Seifi, A.R. Effects of district heating networks on optimal energy flow of multi-carrier systems. Renew. Sustain. Energy Rev. 2016, 59, 379-387. [CrossRef]

53. Unsihuay, C.; Marangon-Lima, J.W.; de Souza, A.C.Z. Short-term operation planning of integrated hydrothermal and natural gas systems. In Proceedings of the 2007 IEEE Lausanne POWERTECH, Proceedings, Lausanne, Switzerland, 1-5 July 2007; pp. 1410-1416.

54. Robertson, E.M.; Alarcon-Rodriguez, A.D.; Galloway, S.J.; Ault, G.W. Outline for an integrated multiple energy carrier model of the UK energy infrastructure. In Proceedings of the 2009 44th International Universities Power Engineering Conference, Glasgow, UK, 1-4 September 2009; pp. 911-915.

55. Galus, M.D.; Andersson, G. Integration of Plug-In Hybrid Electric Vehicles into energy networks. In Proceedings of the 2009 IEEE Bucharest PowerTech: Innovative Ideas Toward the Electrical Grid of the Future, Bucharest, Romania, 28 June-2 July 2009.

56. Fan, H.; Chen, Q.; Liu, W.; Li, J.; Chen, Y. Optimal scheduling for energy hub in power markets. In Proceedings of the IEEE PES Innovative Smart Grid Technologies Conference Europe, Melbourne, VIC, Australia, 28 November-1 December 2016; pp. 127-131.

57. Pazouki, S.; Haghifam, M. Market based short term scheduling in energy hub in presence of responsive loads and renewable resources. In Proceedings of the 22nd International Conference on Electricity Distribution, Stockholm, Sweden, 10-13 June 2013; pp. 1-4.

58. Pazouki, S.; Haghifam, M.R.; Olamaei, J. Short term scheduling of multi carrier systems through interruptible load and Energy Storage toward future sustainable energy needs. In Proceedings of the 2013 8th International Conference on Electrical and Electronics Engineering (ELECO), Bursa, Turkey, 28-30 November 2013; pp. 77-81.

59. Haghifam, M.R.; Pazouki, S.; Pazouki, S. Renewables and Plug in Electric Vehicles modeling on electricity and gas infrastructures scheduling in presence of responsive demand. In Proceedings of the 2013 3rd International Conference on Electric Power and Energy Conversion Systems, EPECS 2013, Istanbul, Turkey, 2-4 October 2013; pp. 1-5.

60. Rastegar, M.; Fotuhi-Firuzabad, M. Optimal charge scheduling of PHEV in a multi-carrier energy home. In Proceedings of the 2014 14th International Conference on Environment and Electrical Engineering, EEEIC 2014-Conference Proceedings, Krakow, Poland, 10-12 May 2014; pp. 199-203.

61. Pazouki, S. Scheduling of Energy Hubs Including CCHP, Solar and Energy Storages in Different Climates. In Proceedings of the 20th Iranian Electrical Power Distribution Conference, Zahedan, Iran, 28-29 April 2015; pp. 28-29.

62. Xu, X.; Jia, H.; Wang, D.; Yu, D.C.; Chiang, H.D. Hierarchical energy management system for multi-source multi-product microgrids. Renew. Energy 2015, 78, 621-630. [CrossRef]

63. Ramírez-Elizondo, L.M.; (Bob) Paap, G.C. Scheduling and control framework for distribution-level systems containing multiple energy carrier systems: Theoretical approach and illustrative example. Int. J. Electr. Power Energy Syst. 2015, 66, 194-215. [CrossRef]

64. Vaccaro, A.; Pisani, C.; Zobaa, A.F. Affine arithmetic-based methodology for energy hub operation-scheduling in the presence of data uncertainty. IET Gener. Transm. Distrib. 2015, 9, 1544-1552. [CrossRef] 
65. Moghaddam, I.G.; Saniei, M.; Mashhour, E. A comprehensive model for self-scheduling an energy hub to supply cooling, heating and electrical demands of a building. Energy 2016, 94, 157-170. [CrossRef]

66. Pazouki, S.; Haghifam, M.R. Optimal planning and scheduling of energy hub in presence of wind, storage and demand response under uncertainty. Int. J. Electr. Power Energy Syst. 2016, 80, 219-239. [CrossRef]

67. Morvaj, B.; Knezović, K.; Evins, R.; Marinelli, M. Integrating multi-domain distributed energy systems with electric vehicle PQ flexibility: Optimal design and operation scheduling for sustainable low-voltage distribution grids. Sustain. Energy Grids Netw. 2016, 8, 51-61. [CrossRef]

68. Zidan, A.; Gabbar, H.A. Optimal scheduling of energy hubs in interconnected multi energy systems. In Proceedings of the 2016 4th IEEE International Conference on Smart Energy Grid Engineering, SEGE 2016, Oshawa, ON, Canada, 21-24 August 2016; pp. 164-169.

69. Moghaddam, I.G.; Saniei, M.; Mashhour, E. Improvement of energy performance employing electrical heatpump in scheduling a residential energy hub. Int. Trans. Electr. Energy Syst. 2016, 26, 2618-2642. [CrossRef]

70. Pazouki, S. Hourly Scheduling of Energy Hub Including CCHP, Solar and Energy Storage in Mild and Warm Climates. Majlesi J. Energy Manag. 2016, 5, 15-20.

71. Moghaddam, I.G.; Saniei, M.; Mashhour, E. A Multi Slack Optimization Model for Scheduling Energy Hubs in Smart Grids. J. Power Technol. 2016, 98, 287-295.

72. Baghaee, H.R.; Mirsalim, M.; Gharehpetian, G.B.; Talebi, H.A. Reliability/cost-based multi-objective Pareto optimal design of stand-alone wind/PV/FC generation microgrid system. Energy 2016, 115, 1022-1041. [CrossRef]

73. Zlotnik, A.; Roald, L.; Backhaus, S.; Chertkov, M.; Andersson, G. Coordinated Scheduling for Interdependent Electric Power and Natural Gas Infrastructures. IEEE Trans. Power Syst. 2017, 32, 600-610. [CrossRef]

74. El-Zonkoly, A. Optimal scheduling of observable controlled islands in presence of energy hubs. Electr. Power Syst. Res. 2017, 142, 141-152. [CrossRef]

75. Dolatabadi, A.; Mohammadi-Ivatloo, B. Stochastic risk-constrained scheduling of smart energy hub in the presence of wind power and demand response. Appl. Therm. Eng. 2017, 123, 40-49. [CrossRef]

76. Chen, H.; Zhang, R.; Bai, L.; Jiang, T.; Li, G.; Jia, H.; Li, X. Stochastic Scheduling of Integrated Energy Systems Considering Wind Power and Multienergy Loads Uncertainties. J. Energy Eng. 2017, 143, 1-9. [CrossRef]

77. Arnold, M.; Negenborn, R.R.; Andersson, G.; de Schutter, B. Model-based predictive control applied to multi-carrier energy systems. In Proceedings of the 2009 IEEE Power \& Energy Society General Meeting, Calgary, AB, Canada, 26-30 July 2009; Volume 19.

78. Arnold, M.; Andersson, G. Model predictive control of energy storage including uncertain forecasts. In Proceedings of the Power Systems Computation Conference (PSCC), Stock, Sweden, 22 -26 August 2011.

79. Arnold, M.; Negenborn, R.R.; Andersson, G.; de Schutter, B. Distributed control applied to combined electricity and natural gas infrastructures. In Proceedings of the 2008 1st International Conference on Infrastructure Systems and Services: Building Networks for a Brighter Future, INFRA 2008, Rotterdam, The Netherlands, 10-12 November 2008; p. 6.

80. Adamek, F. Optimal multi energy supply for regions with increasing use of renewable resources. In Proceedings of the 2008 IEEE Energy 2030 Conference, ENERGY 2008, Atlanta, GA, USA, 17-18 November 2008; pp. 1-6.

81. Arnold, M.; Kienzle, F.; Andersson, G. Distributed Control Applied to Multi-Energy Generation Portfolios. In Smart Energy Strategies: Meeting the Climate Change Challeng; Energy Science Center ETH Zurich, Ed.; vdf Hochschulverlag AG, an der ETH Zurich: Zurich, Switzerland, 2008; p. 153.

82. Carradore, L.; Turri, R. Modeling and simulation of multi-vector energy systems. In Proceedings of the 2009 IEEE Bucharest PowerTech: Innovative Ideas Toward the Electrical Grid of the Future, Bucharest, Romania, 28 June-2 July 2009.

83. Ramirez-Elizondo, L.M.; Paap, G.C. Unit commitment in multiple energy carrier systems. In Proceedings of the 41st North American Power Symposium, NAPS 2009, Starkville, MS, USA, 4-6 October 2009; pp. 1-6.

84. Barsali, S.; Poli, D.; Scalari, S.; Carradore, L.; Turri, R. Integration of process-side energy storage and active distribution networks: Technical and economical optimisation. In Proceedings of the 20th International Conference and Exhibition on Electricity Distribution (CIRED 2009), Prague, Czech Republic, 8-11 June 2009; pp. 1-4. 
85. Carradore, L.; Turri, R. Optimal co-ordinated operation of distributed multi-generation in active distribution networks. In Proceedings of the 2009 44th International Universities Power Engineering Conference (UPEC), Glasgow, UK, 1-4 September 2009; pp. 125-129.

86. Arnold, M.; Negenborn, R.R.; Andersson, G.; De Schutter, B. Multi-area predictive control for combined electricity and natural gas systems. In Proceedings of the European Control Conference 2009, Budapest, Hungary, 23-26 August 2009; Volume 41, pp. 1408-1413.

87. Arnold, M.; Andersson, G. Investigating Renewable Infeed in Residential Areas. In Proceedings of the 2010 IEEE Power and Energy Society General Meeting, Providence, RI, USA, 25-29 July 2010; pp. 1-8.

88. Ramirez-Elizondo, L.; Velez, V.; Paap, G.C. A technique for unit commitment in multiple energy carrier systems with storage. In Proceedings of the 2010 9th Conference on Environment and Electrical Engineering, EEEIC 2010, Prague, Czech Republic, 16-19 May 2010; pp. 106-109.

89. Arnold, M.; Negenborn, R.R.; Andersson, G.; de Schutter, B. Distributed Predictive Control for Energy Hub Coordination in Coupled Electricity and Gas Networks. In Intelligent Infrastructures; Negenborn, R.R., Lukszo, Z., Hellendoorn, H., Eds.; Springer: London, UK, 2010; p. 546.

90. Velez, V. Design of a Control Strategy for Optimal Operation of an Autonomous Distributed Generation System for Electricity and Heat. Master's Thesis, Delft University of Technology, Delft, The Netherlands, 2010.

91. Almassalkhi, M.; Hiskens, I. Cascade mitigation in energy hub networks. In Proceedings of the IEEE Conference on Decision and Control, Orlando, FL, USA, 12-15 December 2011; pp. 2181-2188.

92. Almassalkhi, M.; Hiskens, I. Optimization framework for the analysis of large-scale networks of energy hubs. In Proceedings of the 2011 17th Power Systems Computation Conference (PSCC), Stockholm, Sweden, 22-26 August 2011; pp. 1-7.

93. Parisio, A.; del Vecchio, C.; Velotto, G. Robust Optimization of operations in energy hub. In Proceedings of the IEEE Conference on Decision and Control, Orlando, FL, USA, 12-15 December 2011; pp. 4943-4948.

94. Sheikhi, A.; Ranjbar, A.M.; Safe, F. Optimal Dispatch of a Multiple Energy Carrier System Equipped With a CCHP. In Proceedings of the International Conference on Renewable Energies and Power Quality, Gran Canaria, Spain, 13-15 April 2011; Volume 1, pp. 1-6.

95. Arnold, M. On Predictive Control for Coordination in Multi-Carrier Energy Systems. Ph.D. Thesis, ETH Zurich, Zurich, Switzerland, 2011.

96. Velez, V.; Ramirez-Elizondo, L.; Paap, G.C. Control strategy for an autonomous energy system with electricity and heat flows. In Proceedings of the 2011 16th International Conference on Intelligent System Applications to Power Systems, ISAP 2011, Hersonissos, Greece, 25-28 September 2011; pp. 1-6.

97. Ulbig, A.; Arnold, M.; Chatzivasileiadis, S.; Andersson, G. Framework for multiple time-scale cascaded MPC application in power systems. IFAC Proc. Vol. 2011, 18, 10472-10480. [CrossRef]

98. Akgun, E.; Cakmakci, M. Development of a supervisory controller for residential energy management problems. In Proceedings of the American Control Conference, Montreal, QC, Canada, 27-29 June 2012; pp. 1482-1487.

99. Pazouki, S.; Haghifam, M.; Olamaei, J. Effect of Wind Turbine, Solar Cells and Storages in Short Term Operation of Coupled Electricity and Gas Infrastructures in Different Climates. Int. J. Smart Electr. Eng. 2013, 2, 159-165.

100. Almassalkhi, M.R. Optimization and Model-predictive Control for Overload Mitigation in Resilient Power Systems. Ph.D. Thesis, University of Michigan, Ann Arbor, Michigan, 2013.

101. Yu, D.; Lian, B.; Dunn, R. Using Control Methods to Model Energy Hub Systems. In Proceedings of the Power Engineering Conference (UPEC), Cluj-Napoca, Romania, 2-5 September 2014; pp. 1-4.

102. Moeini-Aghtaie, M.; Dehghanian, P.; Fotuhi-Firuzabad, M.; Abbaspour, A. Multiagent genetic algorithm: An online probabilistic view on economic dispatch of energy hubs constrained by wind availability. IEEE Trans. Sustain. Energy 2014, 5, 699-708. [CrossRef]

103. Soroudi, A.; Mohammadi-Ivatloo, B.; Rabiee, A. Energy hub management with intermittent wind power. In Large Scale Renewable Power Generation; Springer: Singapore, 2014; pp. 413-438.

104. Kampouropoulos, K.; Andrade, F.; Sala, E.; Romeral, L. Optimal control of energy hub systems by use of SQP algorithm and energy prediction. In Proceedings of the IECON Proceedings (Industrial Electronics Conference), Dallas, TX, USA, 29 October-1 November 2014; pp. 221-227.

105. Moazeni, S.; Powell, W.B.; Hajimiragha, A.H. Mean-conditional value-at-risk optimal energy storage operation in the presence of transaction costs. IEEE Trans. Power Syst. 2015, 30, 1222-1232. [CrossRef] 
106. Skarvelis-Kazakos, S.; Papadopoulos, P.; Unda, I.G. Agent-based control of multiple energy carriers and energy hubs. In Proceedings of the IEEE PES Innovative Smart Grid Technologies Conference Europe, Istanbul, Turkey, 12-15 October 2014.

107. Moeini-Aghtaie, M.; Abbaspour, A.; Fotuhi-Firuzabad, M.; Dehghanian, P. Optimized Probabilistic PHEVs Demand Management in the Context of Energy Hubs. IEEE Trans. Power Deliv. 2015, 30, 996-1006. [CrossRef]

108. Mitchell, P.; Skarvelis-Kazakos, S. Control of a biogas co-firing CHP as an Energy Hub. In Proceedings of the Universities Power Engineering Conference, Stoke-on-Trent, UK, 1-4 September 2015; pp. 1-6.

109. Rastegar, M.; Fotuhi-Firuzabad, M.; Lehtonen, M. Home load management in a residential energy hub. Electr. Power Syst. Res. 2015, 119, 322-328. [CrossRef]

110. Salimi, M.; Adelpour, M.; Adeh, S.V.; Ghasemi, H. Optimal planning of energy hubs in interconnected energy systems: A case study for natural gas and electricity. IET Gener. Transm. Distrib. 2015, 9, 695-707. [CrossRef]

111. Skarvelis-Kazakos, S.; Papadopoulos, P.; Unda, I.G.; Gorman, T.; Belaidi, A.; Zigan, S. Multiple energy carrier optimisation with intelligent agents. Appl. Energy 2016, 167, 323-335. [CrossRef]

112. Teng, F.; Sun, Q.; Zhang, H. Coordinated optimization control strategy for we-energy in energy internet. In Proceedings of the 28th Chinese Control and Decision Conference, CCDC 2016, Yinchuan, China, 28-30 May 2016; pp. 5004-5008.

113. Hashemi, Z.; Ramezani, A.; Moghaddam, M.P. Energy hub management by using decentralized robust model predictive control. In Proceedings of the 2016 th International Conference on Control, Instrumentation, and Automation, ICCIA 2016, Qazvin, Iran, 27-28 January 2016; pp. 105-110.

114. Hernández-Hernández, C.; Rodríguez, F.; Moreno, J.C.; Mendes, P.R.d.; Normey-Rico, J.E. The use of Model Predictive Control (MPC) in the optimal distribution of electrical energy in a microgrid located in southeastern of Spain: A case study simulation. Renew. Energy Power Qual. J. 2017, 1, 221-226. [CrossRef]

115. Liu, Y.; Gao, S.; Zhao, X.; Zhang, C.; Zhang, N. Coordinated Operation and Control of Combined Electricity and Natural Gas Systems with Thermal Storage. Energies 2017, 10, 917. [CrossRef]

116. Hernández-Hernández, C.; Rodríguez, F.; Moreno, J.; Mendes, P.D.; Normey-Rico, J.; Guzmán, J. The Comparison Study of Short-Term Prediction Methods to Enhance the Model Predictive Controller Applied to Microgrid Energy Management. Energies 2017, 10, 884. [CrossRef]

117. Baghaee, H.R.; Mirsalim, M.; Gharehpetian, G.B.; Talebi, H.A. Decentralized sliding mode control of WG/PV/FC microgrids under unbalanced and nonlinear load conditions for on-and off-grid modes. IEEE Syst. J. 2017, 12, 3108-3119. [CrossRef]

118. Baghaee, H.R.; Mirsalim, M.; Gharehpetian, G.B.; Talebi, H.A. A decentralized power management and sliding mode control strategy for hybrid AC/DC microgrids including renewable energy resources. IEEE Trans. Ind. Inf. 2017. [CrossRef]

119. Sheikhi, A.; Ranjbar, A.M.; Oraee, H. Financial analysis and optimal size and operation for a multicarrier energy system. Energy Build. 2012, 48, 71-78. [CrossRef]

120. Moazeni, S.; Miragha, A.; Defourny, B. A Risk-Averse Stochastic Dynamic Programming Approach to Energy Hub Optimal Dispatch. IEEE Trans. Power Syst. 2019, 34, 2169-2178. [CrossRef]

121. Moazeni, S.; Coleman, T.F.; Li, Y. Smoothing and parametric rules for stochastic mean-CVaR optimal execution strategy. Ann. Oper. Res. 2016, 237, 99-120. [CrossRef]

122. Moazeni, S.; Powell, W.B.; Defourny, B.; Bouzaiene-Ayari, B. Parallel nonstationary direct policy search for risk-averse stochastic optimization. INFORMS J. Comput. 2017, 29, 332-349. [CrossRef]

123. Hajimiragha, A.H.; Zadeh, M.R.D.; Moazeni, S. Microgrids frequency control considerations within the framework of the optimal generation scheduling problem. IEEE Trans. Smart Grid 2014, 6, 534-547. [CrossRef]

124. Fabrizio, E.; Filippi, M.; Virgone, J. An hourly modelling framework for the assessment of energy sources exploitation and energy converters selection and sizing in buildings. Energy Build. 2009, 41, 1037-1050. [CrossRef]

125. Martinez-Mares, A.; Fuerte-Esquivel, C. A Unified Gas and Power Flow Analysis in Natural Gas and Electricity Coupled Networks. IEEE Trans. Power Syst. 2012, 27, 2156-2166. [CrossRef]

126. Anderson, L.; Galloway, S.; Stephen, B. Assessment of the impact of different energy mixes in local decentralised energy networks. Proc. Inst. Mech. Eng. Part A J. Power Energy 2013, 227, 105-114. [CrossRef]

127. Martinez-Mares, A.; Fuerte-Esquivel, C.R. A robust optimization approach for the interdependency analysis of integrated energy systems considering wind power uncertainty. IEEE Trans. Power Syst. 2013, 28, 3964-3976. [CrossRef] 
128. Giaouris, D.; Papadopoulos, A.I.; Ziogou, C.; Ipsakis, D.; Voutetakis, S.; Papadopoulou, S.; Seferlis, P.; Stergiopoulos, F.; Elmasides, C. Performance investigation of a hybrid renewable power generation and storage system using systemic power management models. Energy 2013, 61, 621-635. [CrossRef]

129. Orehounig, K.; Evins, R.; Dorer, V.; Carmeliet, J. Assessment of renewable energy integration for a village using the energy hub concept. Energy Procedia 2014, 57, 940-949. [CrossRef]

130. Xu, X.; Hou, K.; Jia, H.; Yu, X. A reliability assessment approach for the urban energy system and its application in energy hub planning. In Proceedings of the IEEE Power and Energy Society General Meeting, Denver, CO, USA, 26-30 July 2015; pp. 1-5.

131. Perera, A.T.D.; Nik, V.M.; Mauree, D.; Scartezzini, J.L. Evaluating the Sensitivity of Grid Integration Level for a Multi Energy Hubs. In Proceedings of the International Conference CISBAT 2015 Future Buildings and Districts-Sustainability from Nano to Urban Scale, Lausanne, Switzerland, 9-11 September 2015; pp. 505-510.

132. Liu, X.; Mancarella, P. Modelling, assessment and Sankey diagrams of integrated electricity-heat-gas networks in multi-vector district energy systems. Appl. Energy 2016, 167, 336-352. [CrossRef]

133. Shabanpour-Haghighi, A.; Seifi, A.R. An integrated steady-state operation assessment of electrical, natural gas, and district heating networks. IEEE Trans. Power Syst. 2016, 31, 3636-3647. [CrossRef]

134. Pazouki, S.; Haghifam, M.R. Utilization analysis of interdependent gas and electricity energy infrastructures within distribution networks. In Proceedings of the 21st Electrical Power Distribution Network Conference, EPDC 2016, Karaj, Iran, 26-27 April 2016; pp. 87-91.

135. Shariatkhah, M.H.; Haghifam, M.R.; Chicco, G.; Parsa-Moghaddam, M. Adequacy modeling and evaluation of multi-carrier energy systems to supply energy services from different infrastructures. Energy 2016, 109, 1095-1106. [CrossRef]

136. Abeysekera, M. Combined Analysis of Coupled Energy Networks. Ph.D. Thesis, Cardiff University, Cardiff, Wales, 2016.

137. Moeini-Aghtaie, M.; Farzin, H.; Fotuhi-Firuzabad, M.; Amrollahi, R. Generalized Analytical Approach to Assess Reliability of Renewable-Based Energy Hubs. IEEE Trans. Power Syst. 2017, 32, 368-377. [CrossRef]

138. Ma, T.; Wu, J.; Hao, L. Energy flow modeling and optimal operation analysis of the micro energy grid based on energy hub. Energy Convers. Manag. 2017, 133, 292-306. [CrossRef]

139. Morvaj, B.; Evins, R.; Carmeliet, J. Decarbonizing the electricity grid: The impact on urban energy systems, distribution grids and district heating potential. Appl. Energy 2017, 191, 125-140. [CrossRef]

140. Egli, K. Analysis of Strategic Behaviour in Combined Electricity and Gas Markets Using Agent-based Computational Economics. Master's Thesis, ETH Zurich, Zurich, Switzerland, 2007.

141. Iggland, E.; Kienzle, F. Preliminary Study on the Effect of Locational Marginal Prices on a Profit-Based Multi-Energy Generation Portfolio. Bachelor's Thesis, ETH Zurich, Zurich, Switzerland, 2008.

142. Kienzle, F.; Andersson, G. Valuing Investments in Multi-Energy Generation Plants under Uncertainty: A Real Options Analysis. In Proceedings of the IAEE European Conference, Vienna, Austria, 7-10 September 2009; pp. 1-17.

143. Schulze, M.; del Granado, P.C. Implementation of Feed-in Tariffs into Multi-Energy Systems. Int. J. Electr. Comput. Energ. Electron. Commun. Eng. 2009, 3, 1004-1010.

144. Kienzle, F. Evaluation of Investments in Multi-Carrier Energy Systems under Uncertainty. Ph.D. Thesis, ETH Zurich, Zurich, Switzerland, 2010.

145. Kienzle, F.; Andersson, G. Location-dependent valuation of energy hubs with storage in multi-carrier energy systems. In Proceedings of the 2010 7th International Conference on the European Energy Market, EEM 2010, Madrid, Spain, 23-25 June 2010.

146. Shireen, W.; Patel, S. Plug-in hybrid electric vehicles in the smart grid environment. In Proceedings of the IEEE PES T\&D 2010, New Orleans, LA, USA, 19-22 April 2010; pp. 1-4.

147. Favre-Perrod, P.; Kienzle, F.; Andersson, G. Modeling and design of future multi-energy generation and transmission systems. Eur. Trans. Electr. Power 2010, 20, 994-1008. [CrossRef]

148. Schulze, M.; Gasparovic, G.; Lee, J. Pricing of multi-energy network flow. In Proceedings of the 2010 IEEE International Energy Conference and Exhibition, EnergyCon 2010, Manama, Bahrain, 18-22 December 2010; pp. 542-547.

149. Zafra-Cabeza, A.; del Real, A.; Arce, A.; Camacho, E.F.; Ridao, M.A.; Bordons, C. A risk-based strategy for power system optimization. In Proceedings of the IEEE Conference on Decision and Control, Atlanta, GA, USA, 15-17 December 2010; pp. 1905-1910. 
150. Kienzle, F.; Ahcin, P.; Andersson, G. Valuing investments in multi-energy conversion, storage, and demand-side management systems under uncertainty. IEEE Trans. Sustain. Energy 2011, 2, 194-202. [CrossRef]

151. Ranjbar, A.M.; Moshari, A.; Oraee, H.; Sheikhi, A. Optimal Operation and Size for an Energy Hub with CCHP. Energy Power Eng. 2011, 03, 641-649. [CrossRef]

152. Fabrizio, E. Feasibility of polygeneration in energy supply systems for health-care facilities under the Italian climate and boundary conditions. Energy Sustain. Dev. 2011, 15, 92-103. [CrossRef]

153. Bahrami, S.; Safe, F. A financial approach to evaluate an optimized combined cooling, heat and power system. Energy Power Eng. 2013, 5, 352-362. [CrossRef]

154. Adamek, F.; Arnold, M.; Andersson, G. On decisive storage parameters for minimizing energy supply costs in multicarrier energy systems. IEEE Trans. Sustain. Energy 2014, 5, 102-109. [CrossRef]

155. le Blond, S.; Li, R.; Li, F.; Wang, Z. Cost and emission savings from the deployment of variable electricity tariffs and advanced domestic energy hub storage management. In Proceedings of the IEEE Power and Energy Society General Meeting, National Harbor, MD, USA, 27-31 July 2014; pp. 1-4.

156. Maroufmashat, A.; Elkamel, A.; Fowler, M.; Sattari, S.; Roshandel, R.; Hajimiragha, A.; Walker, S.; Entchev, E. Modeling and optimization of a network of energy hubs to improve economic and emission considerations. Energy 2015, 93, 2546-2558. [CrossRef]

157. Kamyab, F.; Bahrami, S. Efficient operation of energy hubs in time-of-use and dynamic pricing electricity markets. Energy 2016, 106, 343-355. [CrossRef]

158. Moghaddam, M.P.; Damavandi, M.Y.; Bahramara, S.; Haghifam, M.R. Modeling the Impact of Multi-Energy Players on Electricity Market in Smart Grid Environment. In Proceedings of the 2016 IEEE Innovative Smart Grid Technologies-Asia (ISGT-Asia), Melbourne, VIC, Australia, 28 November-1 December 2016; pp. 1-6.

159. Facchinetti, E.; Sulzer, S. General Business Model Patterns for Local Energy Management Concepts. Front. Energy Res. 2016, 4, 1-12. [CrossRef]

160. Sheikhi, A.; Rayati, M.; Ranjbar, A.M. Demand side management for a residential customer in multi-energy systems. Sustain. Cities Soc. 2016, 22, 63-77.

161. Beigvand, S.D.; Abdi, H.; la Scala, M. A general model for energy hub economic dispatch. Appl. Energy 2017, 190, 1090-1111. [CrossRef]

162. Majidi, M.; Nojavan, S.; Zare, K. A cost-emission framework for hub energy system under demand response program. Energy 2017, 134, 157-166. [CrossRef]

163. Li, R.; Chen, L.; Zhao, B.; Wei, W.; Liu, F.; Xue, X.; Shengwei, M.; Yuan, T. Economic Dispatch of an Integrated Heat-Power Energy Distribution System with a Concentrating Solar Power Energy Hub. J. Energy Eng. 2017, 143, 1-11. [CrossRef]

164. Al Rafea, K. Utilizing ' Power-to-Gas ' Technology for Storing Energy and to Optimize the Synergy between Environmental Obligations and Economical Requirements. Ph.D. Thesis, University of Waterloo, Waterloo, ON, Canada, 2017.

165. Sharif, A.; Almansoori, A.; Fowler, M.; Elkamel, A.; Alrafea, K. Design of an energy hub based on natural gas and renewable energy sources. Int. J. Energy Res. 2014, 38, 363-373. [CrossRef]

166. Maniyali, Y.; Almansoori, A.; Fowler, M.; Elkamel, A. Energy hub based on nuclear energy and hydrogen energy storage. Ind. Eng. Chem. Res. 2013, 52, 7470-7481. [CrossRef]

167. Qiblawey, H.M.; Banat, F. Solar thermal desalination technologies. Desalination 2008, 220, 633-644. [CrossRef]

168. Younas, O. Desalination of Seawater/Brackish by Multi-Effect Solar Still Coupled with a Point Focus Fresnel Lens. Master's Thesis, The Petroleum Institute, Abu Dhabi, UAE, 2013.

169. Jones, L.E.; Tsuchida, T.B. Renewable Energy Integration; Springer: Singapore, Singapore, 2014.

170. Akella, A.K.; Saini, R.P.; Sharma, M.P. Social, economical and environmental impacts of renewable energy systems. Renew. Energy 2009, 34, 390-396. [CrossRef]

171. Abbasi, S.A.; Abbasi, N. The likely adverse environmental impacts of renewable energy sources. Appl. Energy 2000, 65, 121-144. [CrossRef]

172. International Energy Agency. Benign Energy?: The Environmental Implications of Renewables; OECD: Paris, France, 1998.

173. Chicco, G.; Mancarella, P. A unified model for energy and environmental performance assessment of natural gas-fueled poly-generation systems. Energy Convers. Manag. 2008, 49, 2069-2077. [CrossRef] 
174. Galus, M.D.; Waraich, R.A.; Balmer, M.; Andersson, G.; Axhausen, K.W. A Framework for Investigating the Impact of PHEVS; ETH Zurich Research Collection: Zurich, Switzerland, 2009; p. 9.

175. Orehounig, K.; Mavromatidis, G.; Evins, R.; Dorer, V.; Carmeliet, J. Towards an energy sustainable community: An energy system analysis for a village in Switzerland. Energy Build. 2014, 84, 277-286. [CrossRef]

176. I, R.L.; Chen, L.; Yuan, T.; I, C.L. Optimal dispatch of zero-carbon-emission micro Energy Internet integrated with non-supplementary fired compressed air energy storage system. J. Mod. Power Syst. Clean Energy 2016, 4, 566-580.

177. Fuentes-Cortés, L.F.; Ma, Y.; MaríaPonce-Ortega, J.; Ruiz-Mercado, G.; Zavala, V.M. Valuation of water and emissions in energy systems. Appl. Energy 2016, 210, 518-528. [CrossRef]

178. Geidl, M.; Andersson, G. Optimal power flow of multiple energy carriers. IEEE Trans. Power Syst. 2007, 22, 145-155. [CrossRef]

179. Jiayi, H.; Chuanwen, J.; Rong, X. A review on distributed energy resources and MicroGrid. Renew. Sustain. Energy Rev. 2008, 12, 2465-2476. [CrossRef]

180. Schulze, M.; Friedrich, L.; Gautschi, M. Modeling and optimization of renewables: Applying the energy hub approach. In Proceedings of the 2008 IEEE International Conference on Sustainable Energy Technologies, ICSET 2008, Singapore, Singapore, 24-27 Noveber 2008; pp. 83-88.

181. Hemmes, K.; Zachariah-wolff, J.L.; Geidl, M.; Andersson, G. Towards multi-source multi-product energy systems. Int. J. Hydrog. Energy 2007, 32, 1332-1338. [CrossRef]

182. Maroufmashat, A.; Elkamel, A.; Khavas, S.S.; Fowler, M.; Roshandel, R.; Elsholkami, M. Development of the energy hub networks based on distributed energy technologies. In Proceedings of the Summer Computer Simulation Conference, Chicago, IL, USA, 26-29 July 2015; Volume 47, pp. 216-223.

183. del Real, A.J.; Arce, A.; Bordons, C. Solar-hydrogen residential power system considering seasonal weather variations. IFAC Proc. Vol. 2010, 1, 169-174. [CrossRef]

184. Anastasiadis, A.G.; Argyropoulou, V.M.; Pagonis, K.D.; Hatziargyriou, N.D. Losses in a LV-Microgrid with the Presence of Reactive Power and CHP Units. In Proceedings of the 8th Mediterranean Conference on Power Generation, Transmission, Distribution and Energy Conversion (MEDPOWER 2012), Cagliari, Italy, 1-3 October 2012; p. 34.

185. Schulze, M.; del Granado, P. Optimization modeling in energy storage applied to a multi-carrier system. In Proceedings of the IEEE PES General Meeting, Providence, RI, USA, 25-29 July 2010; pp. 1-7.

186. Robertson, E.; Galloway, S.; Ault, G. The impact of wide spread adoption of high levels of Distributed Generation in domestic properties. In Proceedings of the IEEE Power and Energy Society General Meeting, San Diego, CA, USA, 22-26 July 2012; pp. 1-8.

187. Divya, J.; Østergaard, C.K. Battery energy storage technology for power systems-An overview. Electr. Power Syst. Res. 2009, 79, 511-520. [CrossRef]

188. Galus, M.D.; Andersson, G. Demand Management of Grid Connected Plug-In Hybrid Electric Vehicles (PHEV). In Proceedings of the 2008 IEEE Energy 2030 Conference, Atlanta, GA, USA, 17-18 November 2008; pp. 1-8.

189. Galus, M.D.; Andersson, G. Power system considerations of plug-in hybrid electric vehicles based on a multi energy carrier model. In Proceedings of the 2009 IEEE Power and Energy Society General Meeting, PES '09, Calgary, AB, Canada, 26-30 July 2009.

190. Acha, S.; Green, T.; Shah, N. Impacts of Plug-in Hybrid Vehicles and Combined Heat and Power Technologies on Electric and Gas Distribution Network Losses. In Proceedings of the IEEE PEAIAS Conference on Sustainable Alternative Energy, Valencia, Spain, 28-30 September 2009; pp. 1-7.

191. Syed, F.; Fowler, M.; Wan, D.; Maniyali, Y. An energy demand model for a fleet of plug-in fuel cell vehicles and commercial building interfaced with a clean energy hub. Int. J. Hydrog. Energy 2010, 35, 5154-5163. [CrossRef]

192. Schulze, M.; Riveros, J.Z. Impact of electrical vehicles on strategic planning of energy infrastructure. In Proceedings of the 2010 International Conference on Power System Technology: Technological Innovations Making Power Grid Smarter, POWERCON2010, Hangzhou, China, 24-28 October 2010.

193. Syed, F. Analysis of a Clean Energy Hub Interfaced with a Fleet of Plug-in Fuel Cell Vehicles. Master's Thesis, University of Waterloo, Waterloo, ON, Canada, 2011.

194. Whitefoot, J.W. Optimal Co-Design of Microgrids and Electric Vehicles: Synergies, Simplifications and the Effects of Uncertainty. Ph.D. Thesis, University of Michigan, Ann Arbor, Michigan, 2012. 
195. Waraich, R.A.; Galus, M.D.; Dobler, C.; Balmer, M.; Andersson, G.; Axhausen, K.W. Plug-in hybrid electric vehicles and smart grids: Investigations based on a microsimulation. Transp. Res. Part C Emerg. Technol. 2013, 28, 74-86. [CrossRef]

196. Damavandi, M.Y.; Moghaddam, M.P.; Haghifam, M.-R.; Shafie-khah, M.; Catalao, J.P.S. Stochastic Modeling of Plug-In Electric Vehicles' Parking Lot in Smart Multi-Energy System. In Technological Innovation for Collective Awareness Systems; Camarinha-Matos, L.M., Barrento, N.S., Medonca, R., Eds.; Springer: Costa de Caparica, Portugal, 2014; pp. 332-342.

197. Rastegar, M.; Fotuhi-Firuzabad, M. Load management in a residential energy hub with renewable distributed energy resources. Energy Build. 2015, 107, 234-242. [CrossRef]

198. Yazdani-Damavandi, M.; Moghaddam, M.P.; Haghifam, M.R.; Shafie-Khah, M.; Catalão, J.P.S. Modeling operational behavior of plug-in electric vehicles' parking lot in multienergy systems. IEEE Trans. Smart Grid 2016, 7, 124-135. [CrossRef]

199. Neyestani, N. Sustainable Distribution Network Planning Considering Multi-Energy Systems and Plug-In Electric Vehicles Parking Lots. Ph.D. Thesis, Universidade da Beira Interior, Covilhã, Portugal, 2016.

200. Andrade, F.; Cardenas, J.J.; Romeral, L.; Cusido, J. Modeling and studying of power flow in a parking lot with plug-in vehicles and the impact in the public utility. In Proceedings of the 2012 IEEE PES Innovative Smart Grid Technologies, ISGT 2012, Washington, DC, USA, 16-20 January 2012; pp. 1-7.

201. Braun, H. The phoenix project: Shifting to a solar hydrogen economy by 2020. Chem. Ind. Chem. Eng. Q. 2008, 14, 107-118. [CrossRef]

202. Maroufmashat, A.; Fowler, M.; Khavas, S.S.; Elkamel, A.; Roshandel, R.; Hajimiragha, A. Mixed integer linear programing based approach for optimal planning and operation of a smart urban energy networkto support the hydrogen economy. Int. J. Hydrog. Energy 2015, 41, 7700-7716. [CrossRef]

203. Alanne, K.; Cao, S. Zero-energy hydrogen economy (ZEH2E) for buildings and communities including personal mobility. Renew. Sustain. Energy Rev. 2017, 71, 697-711. [CrossRef]

204. Maroufmashat, A.; Fowler, M.; Elkamel, A.; Khavas, S.S. Optimal Operation of an Energy Hub Network in the Context of Hydrogen Economy. In Proceedings of the 6th International Conference on Hydrogen Production, Oshawa, ON, Canada, 3-6 May 2015; pp. 1-12.

205. Winter, C.J. Hydrogen energy-Abundant, efficient, clean: A debate over the energy-system-of-change. Int. J. Hydrog. Energy 2009, 34, 1. [CrossRef]

206. Nastasi, B.; Basso, G.L. Hydrogen to link heat and electricity in the transition towards future Smart Energy Systems. Energy 2016, 110, 5-22. [CrossRef]

207. Hajimiragha, A.; Fowler, M.W.; Canizares, C.A. Hydrogen economy impact on optimal planning and operation of integrated energy systems. In Proceedings of the International Conference \& Workshop on Micro-Cogeneration Technologies \& Applications, Ottawa, ON, Canada, 29 April-1 May 2008.

208. Proietto, R.; Arnone, D.; Bertoncini, M.; Rossi, A.; La Cascia, D.; Miceli, R.; Riva Sanseverino, E. A novel heuristics-based energy management system for a multi-carrier hub enriched with solid hydrogen storage. In Proceedings of the 5th International Conference on Future Energy Systems, Cambridge, UK, 11-13 June 2014; pp. 231-232.

209. Bucher, M.A.; Haring, T.W.; Bosshard, F.; Andersson, G. Modeling and Economic Evaluation of Power2Gas Technology using Energy Hub Concept. In Proceedings of the 2015 IEEE Power \& Energy Society General Meeting, Denver, CO, USA, 26-30 July 2015; Volume 541, pp. 1-4.

210. Mukherjee, U.; Elsholkami, M.; Walker, S.; Fowler, M.; Elkamel, A.; Hajimiragha, A. Optimal sizing of an electrolytic hydrogen production system using an existing natural gas infrastructure. Int. J. Hydrog. Energy. 2015, 40, 9760-9772. [CrossRef]

211. Maroufmashat, A.; Mukherjee, U.; Ranisau, J.; Barbouti, M.; Trainor, A.; El-Shayeb, H.; Juthani, N.; Fowler, M. Optimization of renewable powered hydrogen micro-grid; Taking in to account economic criteria. In Proceedings of the 4th IEEE International Conference on Smart Energy Grid Engineering, SEGE 2016, Oshawa, ON, Canada, 21-24 August 2016; pp. 252-256.

212. Ban, M.; Yu, J.; Shahidehpour, M.; Yao, Y. Integration of power-to-hydrogen in day-ahead security-constrained unit commitment with high wind penetration. J. Mod. Power Syst. Clean Energy 2017, 5, 337-349. [CrossRef]

213. Mukherjee, U.; Maroufmashat, A.; Narayan, A.; Elkamel, A.; Fowler, M. A Stochastic Programming Approach for the Planning and Operation of a Power to Gas Energy Hub with Multiple Energy Recovery Pathways. Energies 2017, 10, 868. [CrossRef] 
214. Mukherjee, U.; Walker, S.; Maroufmashat, A.; Fowler, M.; Elkamel, A. Development of a pricing mechanism for valuing ancillary, transportation and environmental services offered by a power to gas energy system. Energy 2017, 128, 447-462. [CrossRef]

215. Mukherjee, U.; Maroufmashat, A.; Ranisau, J.; Barbouti, M.; Trainor, A.; Juthani, N.; El-Shayeb, H.; Fowler, M. Techno-economic, environmental, and safety assessment of hydrogen powered community microgrids; case study in Canada. Int. J. Hydrog. Energy 2017, 42, 14333-14349. [CrossRef]

216. Baghaee, H.R.; Mirsalim, M.; Gharehpetian, G.B. Multi-objective optimal power management and sizing of a reliable wind/PV microgrid with hydrogen energy storage using MOPSO. J. Intell. Fuzzy Syst. 2017, 32, 1753-1773. [CrossRef]

217. Chardonnet, C.; Giordano, V.; De Vos, L.; Bart, F.; De Lacroix, T. Study on Early Business Cases for H2 in Energy Storage and More Broadly Power to H2 Applications; FCH-JU: Brussels, Belgium, 2017.

218. Geidl, M. Integrated modeling and optimization of multi-carrier energy systems. Ph.D. Thesis, ETH Zurich, Zurich, Switzerland, 2007.

219. Geidl, M.; Andersson, G. Optimal coupling of energy infrastructures. In Proceedings of the 2007 IEEE Lausanne POWERTECH, Lausanne, Switzerland, 1-5 July 2007; pp. 1398-1403.

220. Camacho, E.F.; Bordons, C.; Johnson, M. Model Predictive Control. Advanced Textbooks in Control and Signal Processing; Springer: London, UK, 1999.

221. Xie, L.; Ilic, M.D. Model predictive dispatch in electric energy systems with intermittent resources. In Proceedings of the 2008 IEEE International Conference on Systems, Man and Cybernetics, Singapore, Singapore, 12-15 October 2008; pp. 42-47.

222. Baocang, D. Modern Predictive Control; CRC Press: Boca Raton, FL, USA, 2009.

223. Aström, K.J.; Murray, R.M. Feedback Systems: An Introduction for Scientists and Engineers; Princeton University Press: Princeton, NJ, USA, 2010.

224. Balashevich, N.V.; Gabasov, R.; Kirillova, F.M. Numerical methods for open loop and closed loop optimization of piecewise linear systems. Comput. Math. Math. Phys. 2001, 41, 1578-1593.

225. del Real, A.J.; Galus, M.D.; Bordons, C.; Andersson, G. Optimal power dispatch of energy networks including external power exchange. In Proceedings of the 2009 European Control Conference (ECC), Budapest, Hungary, 23-26 August 2009; pp. 1-6.

226. Zhang, X.; Che, L.; Shahidehpour, M.; Alabdulwahab, A.S.; Abusorrah, A. Reliability-based optimal planning of electricity and natural gas interconnections for multiple energy hubs. IEEE Trans. Smart Grid 2015, 8, 1658-1667. [CrossRef]

227. Xu, X.; Li, K. Integrated Optimal Power Flow for Distribution Networks in Local and Urban Scales. In Proceedings of the 2016 UKACC 11th International Conference on Control (CONTROL), Belfast, UK, 31 August-2 September 2016; pp. 1-6.

228. Keirstead, J.; Shah, N. Urban Energy Systems: An Integrated Approach; Routledge: Abingdon, UK, 2013.

229. Wolsey, L.A.; Nemhauser, G.L. Integer and Combinatorial Optimizatio, 1st ed.; Wiley-Interscience: Hoboken, NJ, USA, 1999.

230. Williams, H.P. Logic and Integer Programming; Springer: New York, NY, USA, 2009.

231. Dantzig, G.B. Linear Programming and Extensions; Princeton University Press: Princeton, NJ, USA, 2016.

232. Bertsimas, D.; Tsitsiklis, J.N. Introduction to Linear Optimization; Athena Scientific: Nashua, NH, USA, 1997; Volume 30.

233. Bergamini, M.L.; Grossmann, I.; Scenna, N.; Aguirre, P. An improved piecewise outer-approximation algorithm for the global optimization of MINLP models involving concave and bilinear terms. Comput. Chem. Eng. 2008, 32, 477-493. [CrossRef]

234. Bergamini, M.L.; Aguirre, P.; Grossmann, I. Logic-based outer approximation for globally optimal synthesis of process networks. Comput. Chem. Eng. 2005, 29, 1914-1933. [CrossRef]

235. Tsai, J.-F. Global optimization of nonlinear fractional programming problems in engineering design. Eng. Optim. 2005, 37, 302-310. [CrossRef]

236. Martin, A.; Moller, M.; Moritz, S. Mixed integer models for the optimisation of gas networks in the stationary case. Math. Program. Ser. B 2006, 105, 563-582. [CrossRef]

237. Padberg, M. Approximating separable nonlinear functions via mixed zero-one programs. Oper. Res. Lett. 2000, 27, 1-5. [CrossRef] 
238. Vielma, J.P.; Ahmed, S.; Nemhauser, G. A note on 'a superior representation method for piecewise linear functions. INFORMS J. Comput. 2010, 22, 493-497. [CrossRef]

239. Kontogiorgis, S. Practical Piecewise-Linear Approximation for Monotropic Optimization. INFORMS J. Comput. 2000, 12, 324-340. [CrossRef]

240. Topaloglu, H.; Powell, W.B. An algorithm for approximating piecewise linear concave functions from sample gradients. Oper. Res. Lett. 2003, 31, 66-76. [CrossRef]

241. Lin, M.H.; Carlsson, J.G.; Ge, D.; Shi, J.; Tsai, J.F. A review of piecewise linearization methods. Math. Probl. Eng. 2013, 2013, 8. [CrossRef]

242. Camponogara, E.; Nakashima, P. Optimizing gas-lift production of oil wells: Piecewise linear formulation and computational analysis. IIE Trans. 2006, 38, 173-182. [CrossRef]

243. Evins, R.; Orehounig, K.; Dorer, V.; Carmeliet, J. New formulations of the 'energy hub' model to address operational constraints. Energy 2014, 73, 387-398. [CrossRef]

244. Eubank, R.L. Optimal Grouping, Spacing, Stratification, and Piecewise Constant Approximation. 3SIAM Rev. 2006, 30, 404-420. [CrossRef]

245. Glover, F. Improved linear integer programming formulations of nonlinear integer problems. Manag. Sci. 1975, 22, 455-460. [CrossRef]

246. Ba-Shammakh, M.; Elkamel, A.; Douglas, P.; Croiset, E. A mixed-integer non-linear programming model for $\mathrm{CO}_{2}$ emission reduction in the power generation sector. Int. J. Environ. Pollut. 2007, 29, 254-273. [CrossRef]

(C) 2019 by the authors. Licensee MDPI, Basel, Switzerland. This article is an open access article distributed under the terms and conditions of the Creative Commons Attribution (CC BY) license (http://creativecommons.org/licenses/by/4.0/). 